\title{
RELAP5 Analyses of ROSA/LSTF Experiments on AM Measures during PWR Vessel Bottom Small-Break LOCAs with Gas Inflow
}

\author{
Takeshi Takeda \\ Nuclear Safety Research Center, Japan Atomic Energy Agency, Tokai-mura, Naka-gun, Ibaraki-ken 319-1195, Japan \\ Correspondence should be addressed to Takeshi Takeda; takeda.takeshi@jaea.go.jp
}

Received 7 April 2014; Accepted 18 June 2014; Published 1 September 2014

Academic Editor: Arkady Serikov

Copyright ( 2014 Takeshi Takeda. This is an open access article distributed under the Creative Commons Attribution License, which permits unrestricted use, distribution, and reproduction in any medium, provided the original work is properly cited.

\begin{abstract}
RELAP5 code posttest analyses were performed on ROSA/LSTF experiments that simulated PWR 0.2\% vessel bottom small-break loss-of-coolant accidents with different accident management (AM) measures under assumptions of noncondensable gas inflow and total failure of high-pressure injection system. Depressurization of and auxiliary feedwater (AFW) injection into the secondary-side of both steam generators (SGs) as the AM measures were taken $10 \mathrm{~min}$ after a safety injection signal. The primary depressurization rate of $55 \mathrm{~K} / \mathrm{h}$ caused rather slow primary depressurization being obstructed by the gas accumulation in the SG U-tubes after the completion of accumulator coolant injection. Core temperature excursion thus took place by core boil-off before the actuation of low-pressure injection (LPI) system. The fast primary depressurization by fully opening the relief valves in both SGs with continuous AFW injection led to long-term core cooling by the LPI actuation even under the gas accumulation in the SG U-tubes. The code indicated remaining problems in the predictions of break flow rate during two-phase flow discharge period and primary pressure after the gas inflow. Influences of the primary depressurization rate with continuous AFW injection onto the long-term core cooling were clarified by the sensitivity analyses.
\end{abstract}

\section{Introduction}

A small amount of residue including boron around the circumference of two instrument-tube penetration nozzles of pressure vessel lower-head was found at the South Texas Project Unit-1 of pressurized water reactor (PWR) in the US in 2003 [1]. This raised a safety issue concerning vessel structural integrity. Ejection of multiple instrument-tubes due to circumferential cracks at the vessel lower-head nozzles would have caused a small-break loss-of-coolant accident (SBLOCA) at pressure vessel bottom. Liquid-phase break is characterized by fast loss of primary coolant inventory with low primary depressurization. Fletcher and Bolander [2] showed core cooling would continue if break at the vessel lower-head is extremely small through RELAP5 code analyses on instrument-tube ruptures in the Zion-1 PWR in the US. A PWR vessel bottom break simulation test was conducted in 1986 [3] among a series of SBLOCA tests with different location breaks [4] using the large scale test facility (LSTF) [5] under full-pressure conditions in the rig of safety assessment (ROSA) program at Japan Atomic Energy Agency. The LSTF simulates a Westinghouse-type four-loop $3423 \mathrm{MW}$ (thermal) PWR by a full-height and 1/48 volumetrically-scaled two-loop system. Common conditions of the SBLOCA tests include total failure of high-pressure injection (HPI) system of emergency core cooling system (ECCS) and the break size equivalent to $0.5 \%$ cold leg break that corresponds to 2-in. diameter break in the PWR. The SBLOCA tests revealed the break flow rate was larger in the case with the vessel bottom break than in the case with break at a higher elevation (e.g., cold leg) because of single-phase liquid discharge for a longer time, which caused earlier core uncovery and heatup.

Steam generator (SG) secondary-side depressurization through the SG valve(s) with auxiliary feedwater (AFW) injection is one of major accident management (AM) measures to cool and depressurize the primary system because of steam condensation in the SG U-tubes to introduce lowpressure injection (LPI) system of ECCS during SBLOCA especially when HPI system is totally failed [6], as shown 
TABLE 1: Major conditions of LSTF tests.

\begin{tabular}{|c|c|c|c|}
\hline \multirow{2}{*}{ Item } & \multicolumn{3}{|c|}{ Condition } \\
\hline & SP3 & SP4 & SP6 \\
\hline Break size & \multicolumn{3}{|c|}{$0.2 \%$} \\
\hline HPI system & \multicolumn{3}{|c|}{ Total failure } \\
\hline Onset of SG depressurization and AFW injection & \multicolumn{3}{|c|}{10 min after safety injection signal } \\
\hline Action of SG depressurization & $\begin{array}{l}\text { Primary depress. rate } \\
\text { of } 55 \mathrm{~K} / \mathrm{h}\end{array}$ & Full opening of SG RVs & Primary depress. rate of $55 \mathrm{~K} / \mathrm{h}$ \\
\hline Onset of 2nd SG depressurization & None & None & $\begin{array}{l}\text { Pressure vessel liquid level }<\text { hot } \\
\text { leg level }\end{array}$ \\
\hline Action of 2nd SG depressurization & None & None & Full opening of SG RVs \\
\hline AFW injection duration & $30 \mathrm{~min}$ & Continuous injection & Continuous injection (planned) \\
\hline
\end{tabular}

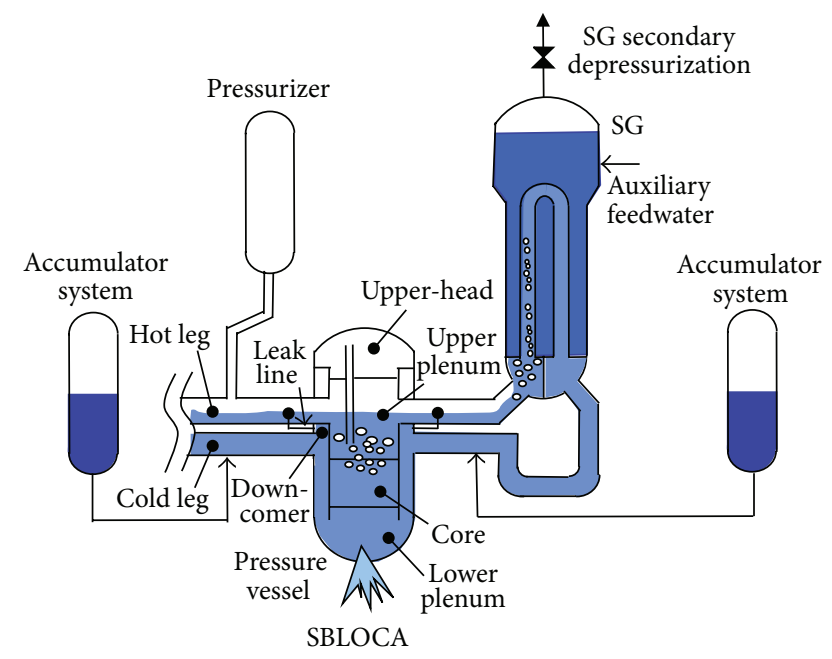

FIGURE 1: Coolant behavior during PWR vessel bottom small-break LOCA with AM measures.

in Figure 1. There have been some experimental studies of SBLOCAs with AM measures by such integral test facilities as Semiscale [7], LOBI [8] and PKL [9]. The obtained data, however, were not sufficient to clarify the effectiveness of AM measures because of such atypical features as small volume and low pressure in the primary system. Asaka et al. [10] investigated influences of primary depressurization rate and onset timing of SG depressurization onto core cooling by the actuation of accumulator (ACC) system of ECCS in PWR cold leg SBLOCAs with different break sizes of 0.5-2.5\% under total failure of HPI system, based on the RELAP5 code analyses of the LSTF tests. When the isolation of ACC system is failed, ingress of noncondensable gas (nitrogen gas) used for pressurization of ACC tanks to the primary system happens after the completion of ACC coolant injection. The noncondensable gas enters cold legs first through ECCS nozzles and migrates to hot legs through the vessel downcomer and hot leg leak simulating lines that connect the downcomer to the hot legs, as shown in Figure 1. The noncondensable gas in the downcomer may flow into the vessel upper-head. The noncondensable gas from the hot legs and SG inlet plena accumulates in SG U-tubes [11]. It is thus important to confirm the effectiveness of AM measures for long-term core cooling by the actuation of LPI system during PWR vessel bottom SBLOCA with the gas inflow.

An OECD/NEA ROSA Project test with the LSTF was performed on a PWR $0.1 \%$ vessel bottom SBLOCA under asymmetric conditions of SG depressurization and AFW injection as the AM measures with the gas inflow and totally failed HPI in 2005 [12, 13]. The PWR electric utilities in Japan have implemented their own AM measures [14]. In the test, the rate of depressurization employed only for SG in loop without pressurizer was adjusted to achieve depressurization rate of $55 \mathrm{~K} / \mathrm{h}$ in the primary system, referring to operator action procedures in PWR accidents where heat removal by $\mathrm{SG}(\mathrm{s})$ is possible. The asymmetric SG depressurization caused unique responses including strongly-asymmetric natural circulation (NC) between two loops under the gas effects. Experimental data, however, are quite limited for AM measures during PWR vessel bottom SBLOCA under influences of noncondensable gas.

Three LSTF tests were conducted simulating PWR vessel bottom SBLOCAs with different conditions for depressurization of and AFW injection into the secondary-side of both SGs as the AM measures under assumptions of the gas inflow and total failure of HPI system in 2002-2003 [15-17]. Table 1 shows the major test conditions. The break size was equivalent to $0.2 \%$ cold leg break to simulate the break of ten instrument-tubes (innerdiameter of 0.4-in. each) of the vessel lower-head. The AM measures were taken 10 min after a safety injection signal, considering a grace period to start an operator action. In a test named SP3, the SG depressurization rate was controlled such that the primary depressurization rate becomes $55 \mathrm{~K} / \mathrm{h}$ using flow control valves at both SGs. The AFW injection duration was then assumed to be $30 \mathrm{~min}$ considering the turbine-driven pump is available. In a test named SP4, the SG secondary-side depressurization was performed by fully opening the SG relief valves (RVs) to 
make the primary depressurization fast. The AFW injection was then assumed to conduct continuously considering the use of the motor-driven pump. In a test named SP6, the SG depressurization rate was controlled to achieve the primary depressurization rate of $55 \mathrm{~K} / \mathrm{h}$ until pressure vessel liquid level becomes below hot leg level first and then the SG RVs were fully opened, being coupled with the AFW injection. Influences of timing on the full opening of the SG RVs onto long-term core cooling were discussed based on results of the three LSTF tests.

In this study, the SP3 and SP4 tests were analyzed by RELAP5/MOD3.2.1.2 code [18] employing a fine-mesh multiple parallel flow channel representation of SG U-tubes for better prediction of nonuniform flow behaviors among the U-tubes, unlike the single flow channel model used in the author's previous studies $[19,20]$. Main objectives of the RELAP5 code posttest analyses are to understand well the observed thermal-hydraulic phenomena and to validate the code predictability. Influences of the primary depressurization rate through the SG depressurization with continuous AFW injection onto long-term core cooling were investigated further by sensitivity analyses, based on the RELAP 5 posttest analyses. This paper describes major results from the LSTF tests and the RELAP5 code analyses.

\section{ROSA/LSTF}

The ROSA/LSTF is the world largest integral test facility designed under full-pressure conditions to investigate multidimensional thermal-hydraulic responses during PWR transients and accidents. The LSTF simulates a Westinghousetype four-loop $3423 \mathrm{MWt}$ PWR by a two-loop system model with full-height and 1/48 in volume. The reference PWR is Tsuruga Unit-2 of Japan Atomic Power Company.

Figure 2 shows the schematic view of the LSTF that is composed of a pressure vessel, pressurizer, and primary loops. Each loop includes an active SG, primary coolant pump, and hot and cold legs. Loops with and without pressurizer are designated as loop-A and loop-B, respectively. Each SG is furnished with 141 full-size U-tubes (inner diameter of $19.6 \mathrm{~mm}$, nine different lengths as shown in Table 2), inlet and outlet plena, boiler section, steam separator, steam dome, steam dryer, main steam line, four downcomer pipes, and other internals. Six U-tubes are instrumented for each SG. Instrumented U-tubes designated as tubes 1 and 6 are short tubes (type 1 in Table 2), tubes 2 and 5 are medium tubes (type 5), and tubes 3 and 4 are long tubes (type 9). The hot and cold legs, $207 \mathrm{~mm}$ in inner-diameter, are sized to conserve the volumetric scale $(2 / 48)$ and the ratio of the length to the square root of pipe diameter to better simulate the flow regime transitions in the primary loops [21].

The LSTF core, $3.66 \mathrm{~m}$ in active height, consists of 1008 electrically heated rods in 24 rod bundles to simulate the fuel rod assembly in the reference PWR. Axial core power profile is a 9-step chopped cosine with a peaking factor of 1.495. The radial power profile is achieved by providing three different (high, mean, and low) power bundles with a maximum peaking factor of 1.51 for high-power bundle.
TABLE 2: Details of LSTF U-tubes in each SG.

\begin{tabular}{lccc}
\hline Type & $\begin{array}{c}\text { Straight } \\
\text { length }(\mathrm{m})\end{array}$ & $\begin{array}{c}\text { Number of } \\
\text { tubes }\end{array}$ & $\begin{array}{c}\text { Instrumented } \\
\text { tubes }\end{array}$ \\
\hline 1 & 9.44 & 21 & \\
2 & 9.59 & 19 & Two short tubes \\
3 & 9.74 & 19 & \\
4 & 9.89 & 19 & \\
5 & 10.04 & 17 & \\
6 & 10.19 & 15 & Two medium tubes \\
7 & 10.34 & 13 & \\
8 & 10.49 & 11 & \\
9 & 10.64 & 7 & Two long tubes \\
\hline
\end{tabular}

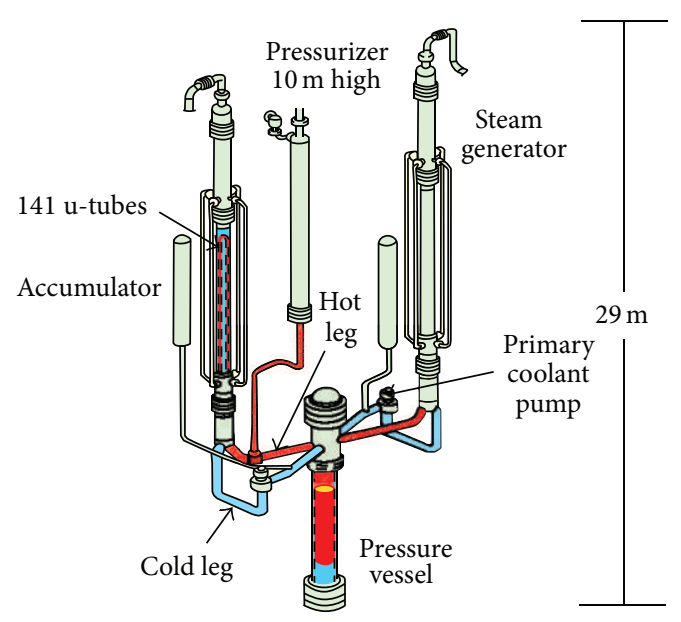

FIgURE 2: Schematic view of ROSA/LSTF.

The LSTF initial core power of $10 \mathrm{MW}$ corresponds to $14 \%$ of the volumetrically-scaled (1/48) PWR nominal core power because of a limitation in the capacity of power supply. The core power after the test initiation is then kept constant at $10 \mathrm{MW}$ for a little while before the core power starts to follow predetermined power decay curve. All the types of ECCS furnished to the reference PWR are equipped in the LSTF.

\section{Experiments and Code Analyses}

3.1. Common Conditions of SP3 and SP4 Tests. The break was simulated by using a $4.6 \mathrm{~mm}$ inner diameter sharpedge orifice mounted at the downstream of a horizontal pipe that was connected to the vessel lower plenum wall, as shown in Figure 3. The orifice size corresponds to $0.2 \%$ of the volumetrically-scaled cross-sectional area of the reference PWR cold leg.

The experiment was initiated by opening a break valve located downstream of the break orifice at time zero. Initial steady-state conditions such as pressurizer pressure and fluid 


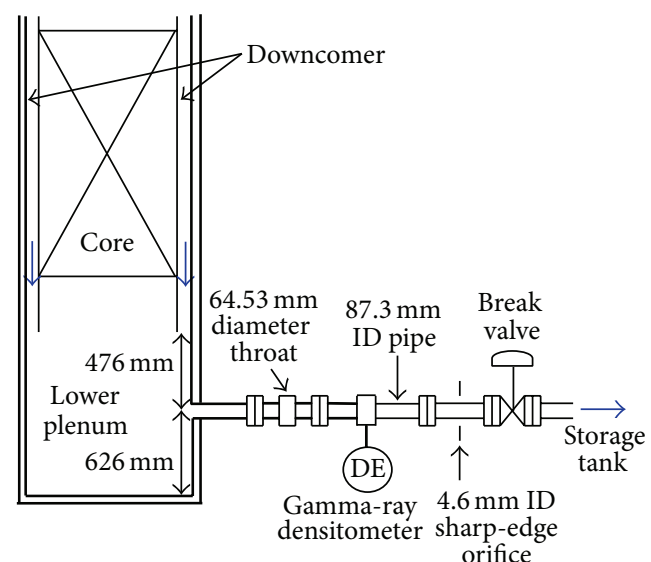

FigURE 3: LSTF vessel bottom break configuration.

temperatures in hot and cold legs were $15.5 \mathrm{MPa}, 598 \mathrm{~K}$, and $562 \mathrm{~K}$, respectively, according to the reference PWR conditions. The LSTF core power decay curve after a scram signal was predetermined based on calculations with the RELAP5 code considering delayed neutron fission power and stored heat in PWR fuel rod [22]. The LSTF core power was maintained at the initial value of $10 \mathrm{MW}$ for $18 \mathrm{~s}$ until the scaled PWR core decay power dropped to $10 \mathrm{MW}$ after the scram signal. The LSTF core power started to decay afterwards following the specified core power decay curve. At a late stage of the experiment when the time of $8000 \mathrm{~s}$ is elapsed after the scram signal, for example, the LSTF core power is $0.81 \mathrm{MW}$ which is well below the initial value. To obtain prototypical initial fluid temperature with this core power, core flow rate was set to $14 \%$ of the scaled nominal flow rate. Initial SG secondary-side pressure was raised to 7.3 $\mathrm{MPa}$ to limit the primary-to-secondary heat transfer rate to $10 \mathrm{MW}$, while $6.1 \mathrm{MPa}$ is nominal value in the reference PWR. Set point pressures for opening and closure of the SG RVs were 8.03 and $7.82 \mathrm{MPa}$, respectively, referring to the corresponding values in the reference PWR. The SG RV was simulated by using a $16.2 \mathrm{~mm}$ inner diameter sharpedge orifice to provide steam flow rate of $2 \mathrm{~kg} / \mathrm{s}$ when SG secondary-side pressure is $8 \mathrm{MPa}$, which corresponds to the volumetrically-scaled rate of the reference PWR. Initial SG secondary-side collapsed liquid level was set to $10.3 \mathrm{~m}$ that corresponds to the medium tube height.

The experiment assumed total failure of HPI system. Loss of off-site power was assumed to occur concurrently with a scram signal when the pressurizer pressure decreases to 12.97 MPa. Depressurization of and AFW injection into the SG secondary-side as the AM measures were taken $10 \mathrm{~min}$ after a safety injection signal when the pressurizer pressure decreases to $12.27 \mathrm{MPa}$. The AFW injection temperature of $310 \mathrm{~K}$ was the same as in the reference PWR. ACC and LPI systems were automatically initiated coolant injection into both cold legs when the primary pressures decrease to 4.51 and 1.24 MPa respectively. The ACC and LPI temperatures were 320 and $310 \mathrm{~K}$, respectively, which are the same as in the reference PWR.

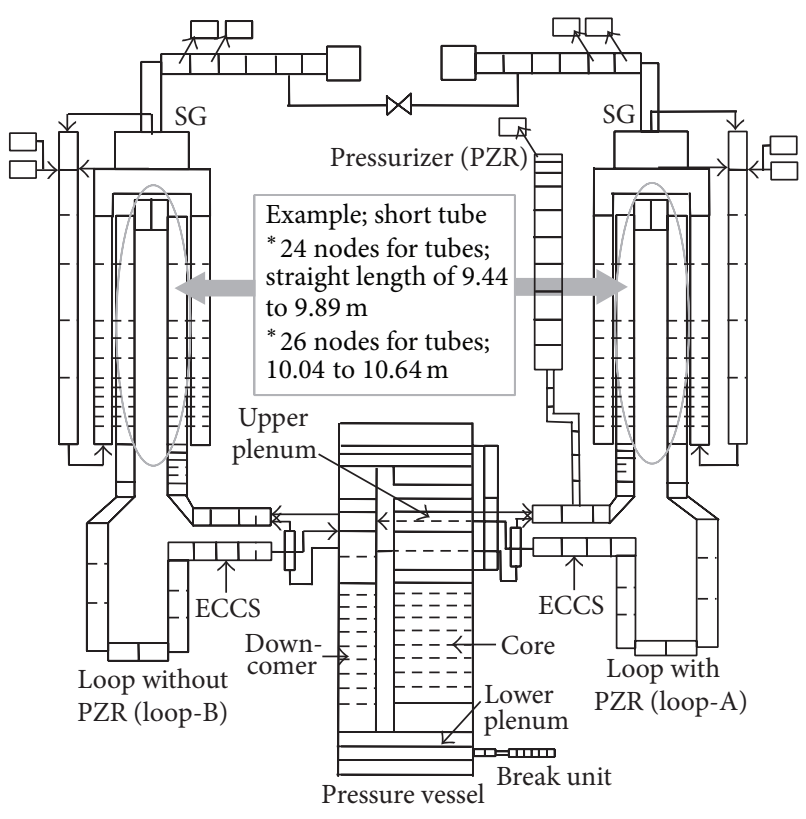

FIGURE 4: Noding schematic of LSTF for RELAP5 analysis.

3.2. RELAP5 Calculation Conditions. The posttest analyses were conducted by the RELAP5/MOD3.2.1.2 code with a two-phase critical flow model [23] to well predict the discharge rate through a sharp-edge orifice. The model employs the Bernoulli incompressible orifice flow equation with a discharge coefficient of 0.61 for single-phase discharge liquid [24] and the maximum bounding flow theory with a discharge coefficient of 0.61 for two-phase discharge flow [25]. This flow theory assumes that no phase change occurs at all along the flow, and that the local slip ratio is equal to $\left(\rho_{\text {liquid }} / \rho_{\text {gas }}\right)^{1 / 3}$, where $\rho$ is the fluid density. A discharge coefficient of 0.84 was used for single-phase discharge steam through the SG valves [26].

Figure 4 shows a noding schematic of LSTF for the RELAP5 analysis. The LSTF system is modeled in onedimensional manner including a pressure vessel, primary loops, pressurizer, SGs, and SG secondary-side system. The break unit from the vessel lower plenum wall to the break orifice shown in Figure 3 was represented by nine horizontal nodes to simulate the corresponding horizontal pipe and throat. The SG U-tubes were modeled by nine parallel flow channels that correspond to nine different lengths of $\mathrm{U}$ tubes, namely, 24 nodes for short-to-medium tubes (straight length of 9.44 to $9.89 \mathrm{~m}$, four cases in Table 2) and 26 nodes for medium-to-long tubes (straight length of 10.04 to $10.64 \mathrm{~m}$, five cases), for better prediction of nonuniform flow behaviors during NC [27, 28]. The riser portion of the SG secondary-side system was modeled by 13 nodes considering the nodes of the SG U-tube flow channels, for better prediction of the SG secondary-side collapsed liquid level.

The core was represented by nine equal-height volumes that are vertically stacked according to 9-step chopped cosine 
power profile along the core length. The radial power distribution was then given considering the peaking factor and the number of high-, mean- and low-power rod bundles. Other initial and boundary conditions were determined according to the LSTF test data.

\subsection{SP3 Test and RELAP5 Analysis under \\ Primary Depressurization Rate of $55 \mathrm{~K} / \mathrm{h}$ and 30 min AFW Injection}

3.3.1. SP3 Test Conditions. The SG depressurization rate was controlled by means of steam discharge through flow control valves at both SGs to achieve the primary depressurization rate of $55 \mathrm{~K} / \mathrm{h}$. The SG pressure drop curve after the onset of AM measures was predetermined based on the primary saturation temperature under an assumption that the primary pressure may closely follow the SG secondary-side pressure. The AFW injection was done into the secondary-side of both SGs for $30 \mathrm{~min}$. The AFW flow rate was at a constant value of $0.7 \mathrm{~kg} / \mathrm{s}$ for each SG that corresponds to the volumetricallyscaled rate of the reference PWR.

\subsubsection{Major Phenomena Observed in SP3 Test. Table 3 sum-} marizes the chronology of major events in the SP3 test. The time-integrated break flow is evaluated from the liquid level increase in the break flow storage tank, and the break flow rate is derived from differential of the integrated break flow. The void fraction at the break-upstream piping is estimated from the measured coolant density using a three-beam gammaray densitometer shown in Figure 3. Break flow turned from single-phase liquid to two-phase flow at about $1300 \mathrm{~s}$ because of the saturation of coolant in the vessel lower plenum, which caused a decrease in the break flow rate (Figure 5). The break flow returned to single-phase liquid at about $9300 \mathrm{~s}$ after the actuation of LPI system.

The primary pressure began to decrease after the break, while the SG secondary-side pressure increased up to about $8 \mathrm{MPa}$ after the closure of main steam isolation valves at both SGs following the scram signal (Figure 7). Small size of break led to a slow primary depressurization. The SG secondary-side pressure fluctuated between 8.03 and 7.82 MPa by cycle opening of the SG RVs until the onset of AM measures. The primary pressure decreased to the SG secondary-side pressure and followed the SG secondaryside pressure afterwards including the depressurization. The SG secondary-side collapsed liquid level increased after the SG main steam isolation valves closure and decreased after the SG depressurization (Figure 8). The SG secondaryside collapsed liquid level gradually recovered by the AFW injection into the SG secondary-side, and gradually decreased after the termination of AFW injection. For example, the SG secondary-side collapsed liquid level dropped to $2 \mathrm{~m}$ at $8070 \mathrm{~s}$ before core uncovery to be mentioned later. The rotation speed of primary coolant pumps decreased according to the loss of off-site power concurrent with the scram signal, and NC was established in both primary loops after the primary coolant pumps stop. The primary loop was in two-phase $\mathrm{NC}$ when the AM measures started. The primary loop flow
TABLE 3: Chronology of major events in LSTF tests.

\begin{tabular}{|c|c|c|c|}
\hline \multirow{2}{*}{ Event } & \multicolumn{3}{|c|}{ Time (s) } \\
\hline & SP3 & SP4 & SP6 \\
\hline Break valve open & 0 & 0 & 0 \\
\hline Scram signal & 250 & 248 & 250 \\
\hline Safety injection signal & 340 & 340 & 340 \\
\hline $\begin{array}{l}\text { Stop of primary coolant } \\
\text { pumps }\end{array}$ & 500 & 499 & 501 \\
\hline $\begin{array}{l}\text { Onset of SG } \\
\text { depressurization and } \\
\text { AFW injection }\end{array}$ & 945 & 941 & 947 \\
\hline $\begin{array}{l}\text { Onset of } 2 \text { nd SG } \\
\text { depressurization }\end{array}$ & None & None & 4550 \\
\hline $\begin{array}{l}\text { Termination of AFW } \\
\text { injection }\end{array}$ & 2750 & None & 6720 \\
\hline Initiation of ACC system & 3260 & 1650 & 3280 \\
\hline $\begin{array}{l}\text { Termination of ACC } \\
\text { system }\end{array}$ & 7090 & 3420 & 5680 \\
\hline $\begin{array}{l}\text { Onset of } \\
\text { noncondensable gas } \\
\text { inflow to primary system }\end{array}$ & 7190 & 3750 & 5990 \\
\hline $\begin{array}{l}\text { SG secondary-side } \\
\text { collapsed liquid level } \\
\text { drop to } 2 \mathrm{~m}\end{array}$ & 8070 & None & None \\
\hline $\begin{array}{l}\text { Initiation of automatic } \\
\text { core power reduction at } \\
\text { maximum cladding } \\
\text { surface temperature } \\
\text { above } 908 \mathrm{~K}\end{array}$ & 9180 & None & 9150 \\
\hline Actuation of LPI system & 9280 & 10370 & 9490 \\
\hline Core power off & 9880 & 11600 & 10065 \\
\hline Break valve closure & 9935 & 11609 & 10069 \\
\hline
\end{tabular}

rate gradually decreased after water column drained in the instrumented U-tubes in nonuniform manner (Figures 9 and 10). One medium tube (tube 2 in Table 2) of SG in loop-B became filled with steam the latest among the instrumented U-tubes. The primary loop flow rate decreased to zero by around $3000 \mathrm{~s}$. The ACC system was initiated coolant injection into cold legs when the primary pressure decreased to 4.51 $\mathrm{MPa}$ (Figure 11), which caused the void fraction increase at the break-upstream piping (Figure 6) due to flashing of the vessel lower plenum fluid. A small drop started in the core collapsed liquid level at around $4700 \mathrm{~s}$ after the upper plenum became empty of liquid (Figures 12 and 13). Collapsed liquid levels recovered at the upper plenum and core in oscillative manner because of intermittent ACC coolant injection. No increase, therefore, occurred in cladding surface temperature of simulated fuel rods during the ACC coolant injection (Figure 14).

The primary depressurization was greatly limited and large pressure difference appeared between the primary and SG secondary sides when noncondensable gas entered the primary system after the completion of ACC coolant injection (Figures 7 and 11), suggesting degradation in the condensation heat transfer in the SG U-tubes. Inadequate 


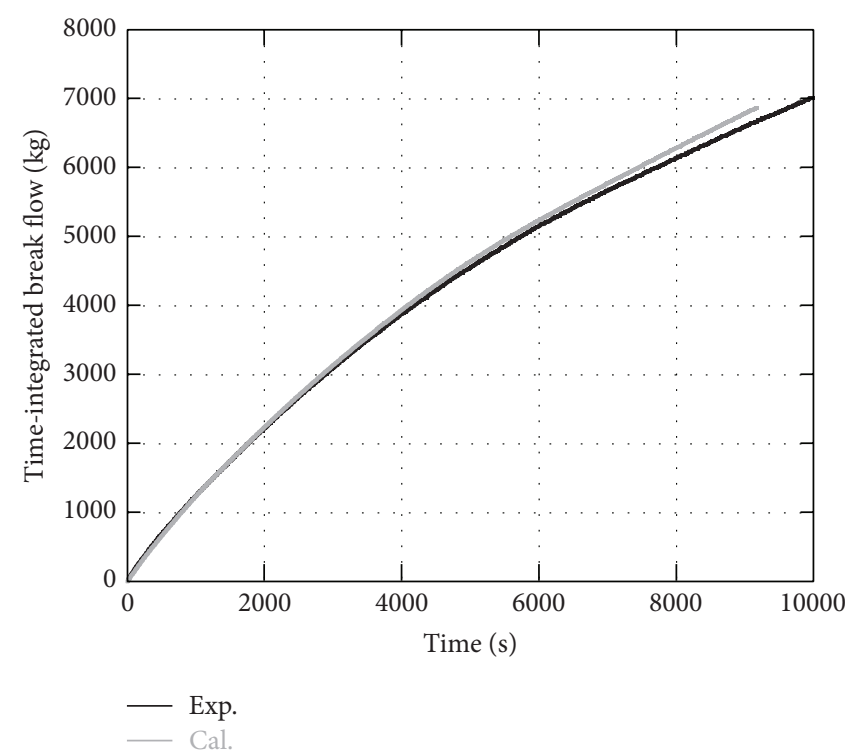

(a) Time-integrated break flow

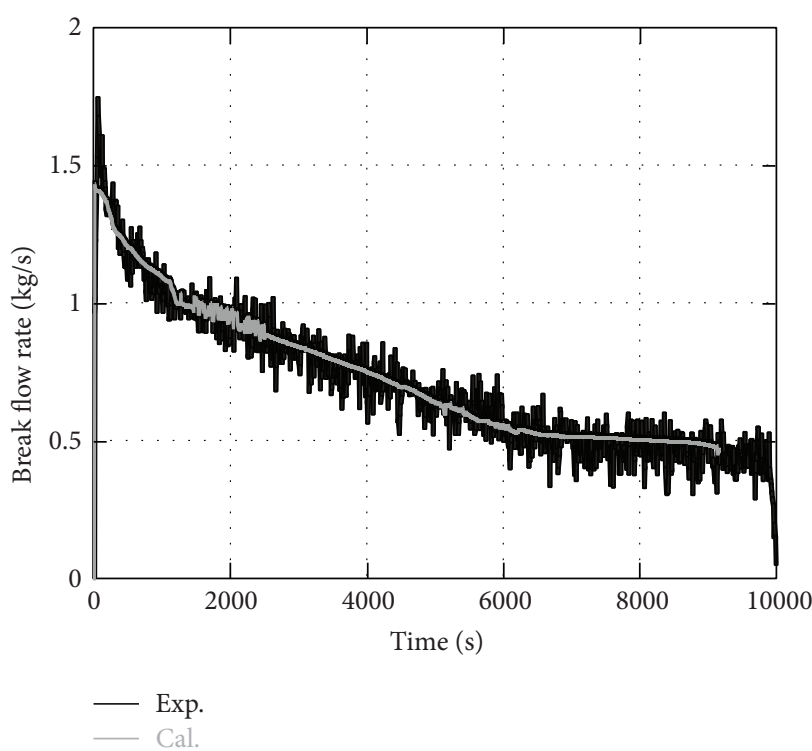

(b) Break flow rate

FIgURE 5: LSTF and RELAP5 results for break flow under $55 \mathrm{~K} / \mathrm{h}$ rate and $30 \mathrm{~min}$ AFW.

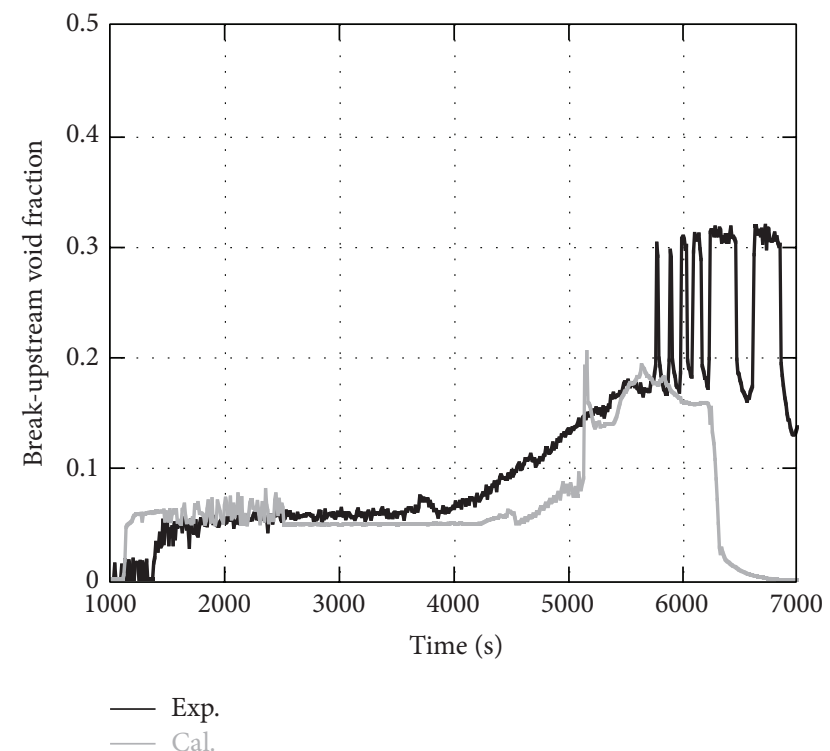

FIGURE 6: LSTF and RELAP5 results for void fraction at breakupstream piping under $55 \mathrm{~K} / \mathrm{h}$ rate and $30 \mathrm{~min}$ AFW.

heat removal due to degradation in the steam condensation may have promoted the formation of large bubble of steamgas mixture at the U-tube top portion. Significant drop started in the upper plenum collapsed liquid level following depletion of the primary coolant inventory after the termination of ACC coolant injection (Figure 12). Core uncovery and heatup took place by core boil-off after the upper plenum became voided again (Figure 13). The SG secondaryside pressure decreased to $0.75 \mathrm{MPa}$ until the onset of core uncovery (Figure 7). The SG secondary-side collapsed liquid

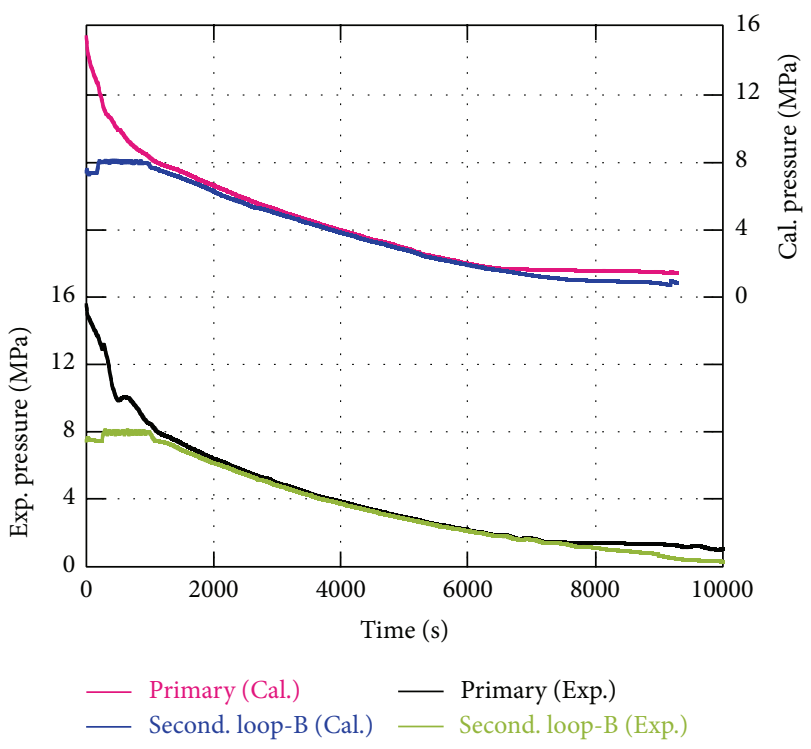

FIGURE 7: LSTF and RELAP5 results for primary and SG secondary pressures under $55 \mathrm{~K} / \mathrm{h}$ rate and $30 \mathrm{~min} \mathrm{AFW}$.

level remained at $1.2 \mathrm{~m}$ when the core uncovery started (Figure 8), which accounts for continuous heat removal by SGs. These may imply the primary pressure would decrease to the LPI actuation pressure of 1.24 MPa with no core heatup in the case without the gas ingress.

As a condition specific to the LSTF, core power was decreased to a certain low level in several steps to protect the electrically heated rods in the core after the maximum cladding surface temperature exceeded predetermined criterion of $908 \mathrm{~K}$. The peak cladding temperature of $920 \mathrm{~K}$ was 


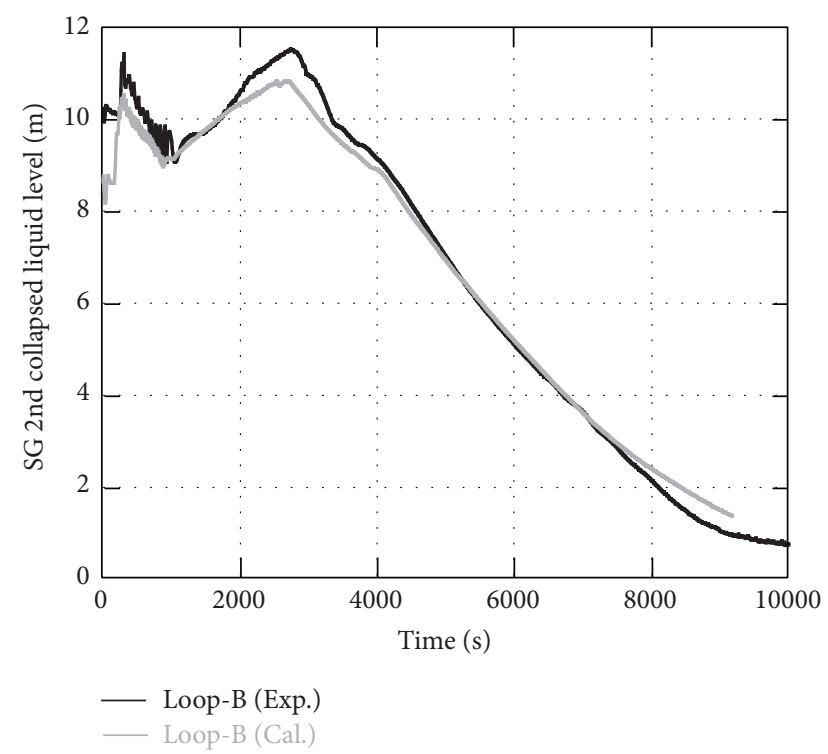

FIGURE 8: LSTF and RELAP5 results for SG secondary-side collapsed liquid level under $55 \mathrm{~K} / \mathrm{h}$ rate and $30 \mathrm{~min} \mathrm{AFW}$.

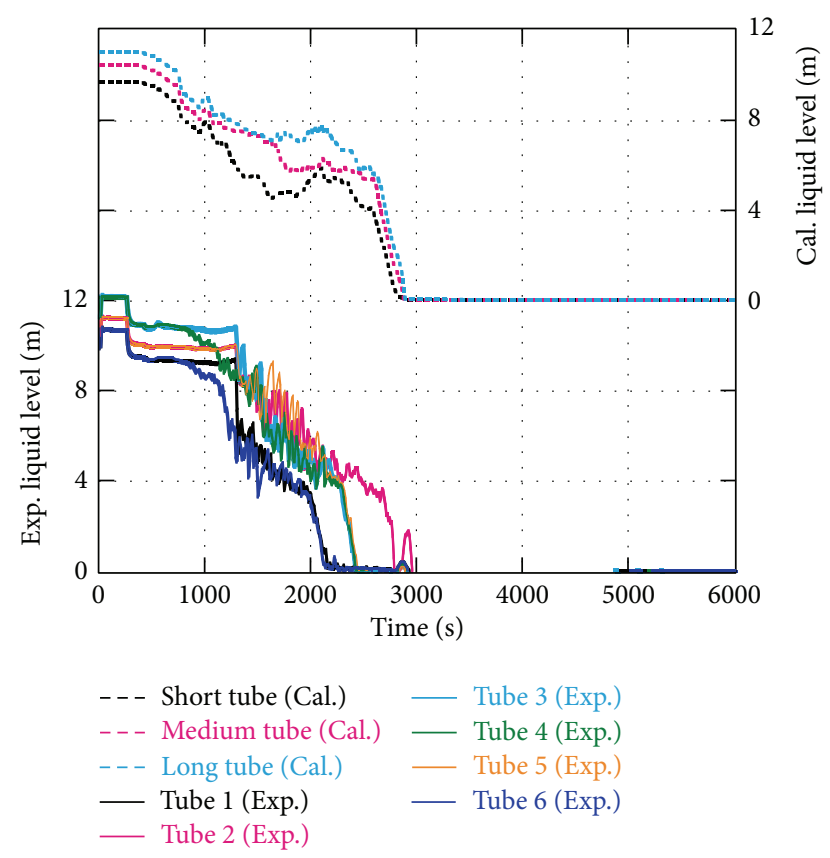

FIGURE 9: LSTF and RELAP5 results for SG-B U-tube upflow side collapsed liquid level under $55 \mathrm{~K} / \mathrm{h}$ rate and $30 \mathrm{~min}$ AFW.

observed at Position 6 (= about $0.4 \mathrm{~m}$ above the core center), as shown in Figure 14. The core power was automatically reduced to $10 \%$ of the predetermined power level as the peak cladding temperature reached $920 \mathrm{~K}$. Due to the automatic reduction of the core power, the whole core was quenched by the actuation of LPI system when the primary pressure decreased to 1.24 MPa.

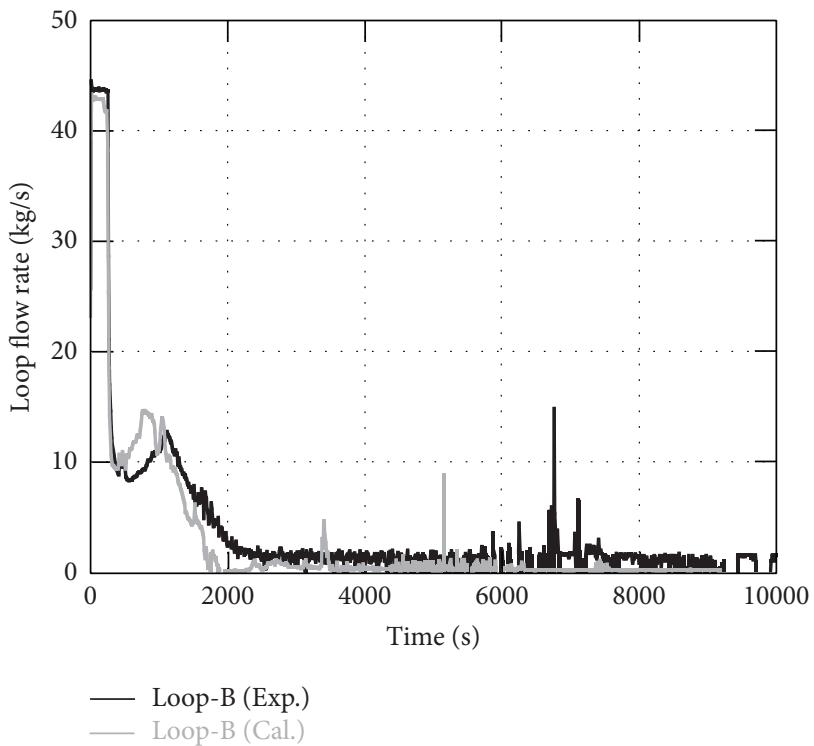

FIGURE 10: LSTF and RELAP5 results for primary loop flow rate under $55 \mathrm{~K} / \mathrm{h}$ rate and $30 \mathrm{~min}$ AFW.

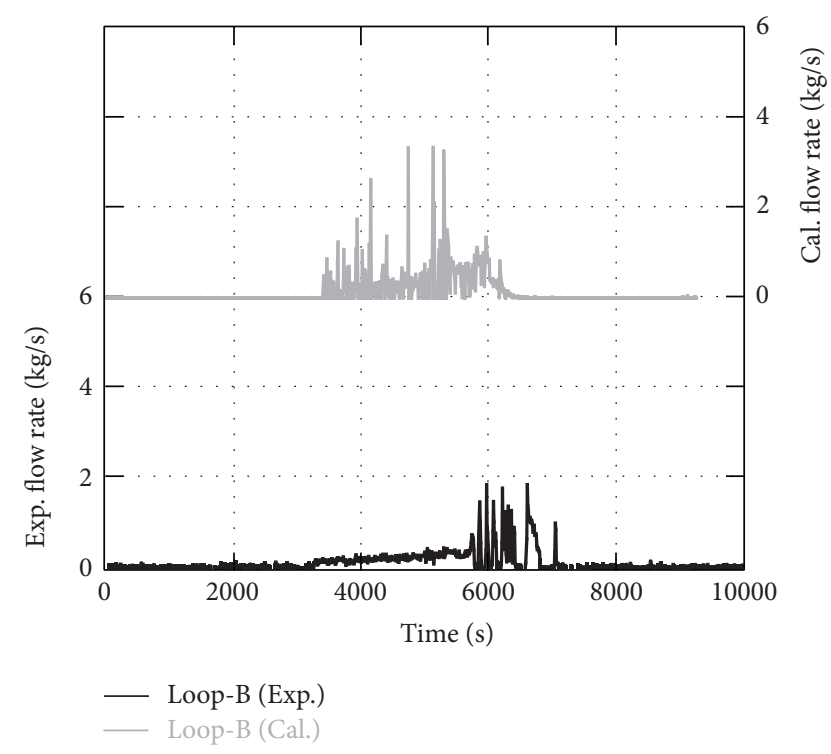

FIGURE 11: LSTF and RELAP5 results for accumulator flow rate under $55 \mathrm{~K} / \mathrm{h}$ rate and $30 \mathrm{~min}$ AFW.

3.3.3. Comparison of Calculated Results with SP3 Test Data. The RELAP5 code predicted well the overall trend of thermalhydraulic response observed in the SP3 test, as shown in Figures 5-14. The posttest analysis was terminated when the maximum cladding surface temperature exceeds the criterion of $908 \mathrm{~K}$.

The SG secondary-side collapsed liquid level was roughly calculated, though with tendencies that the liquid level was underpredicted during the time period around 1900-5000 s and overpredicted after around $7500 \mathrm{~s}$ (Figure 8) probably 


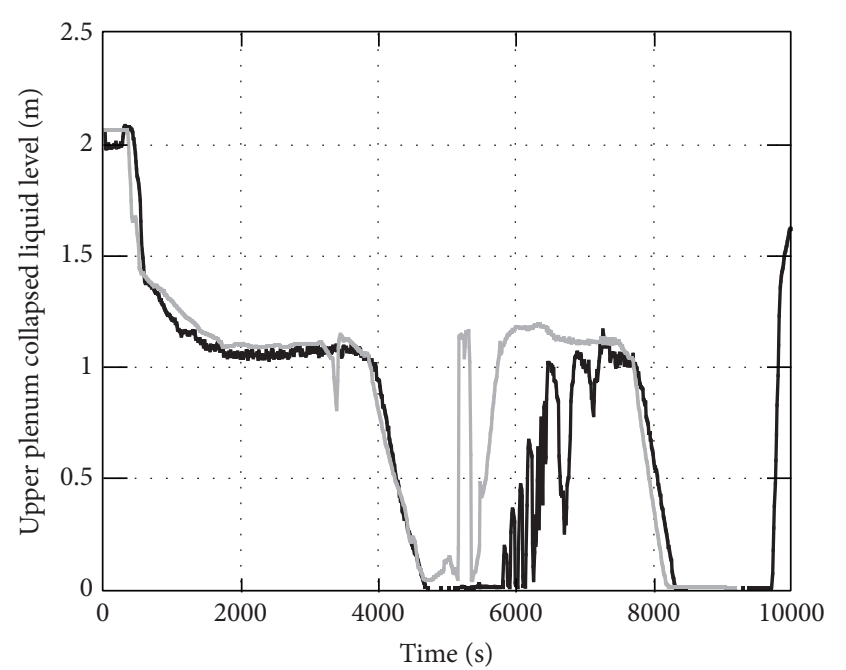

- Exp.

FIGURE 12: LSTF and RELAP5 results for upper plenum collapsed liquid level under $55 \mathrm{~K} / \mathrm{h}$ rate and $30 \mathrm{~min}$ AFW.

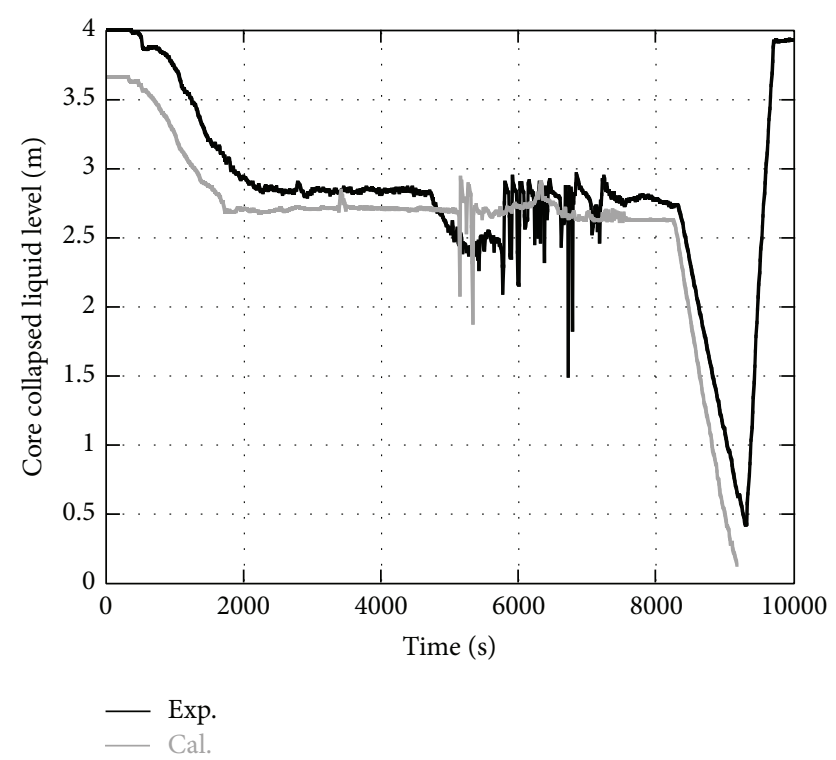

FIGURE 13: LSTF and RELAP5 results for core collapsed liquid level under $55 \mathrm{~K} / \mathrm{h}$ rate and $30 \mathrm{~min} \mathrm{AFW}$.

due to influences of steam discharge rate through the SG valves. The SG U-tube collapsed liquid level was roughly predicted, though with a tendency that the coolant drain started earlier than in the SP3 test (Figure 9). In the twophase $\mathrm{NC}$, the primary loop flow rate became close to zero earlier in the analysis than in the SP3 test (Figure 10). The break flow rate was somewhat overpredicted during twophase flow discharge period partly due to underprediction of void fraction at the break-upstream piping (Figures 5 and 6). The code failed to predict oscillation in the break-upstream void fraction during the time period around $5750-7000 \mathrm{~s}$

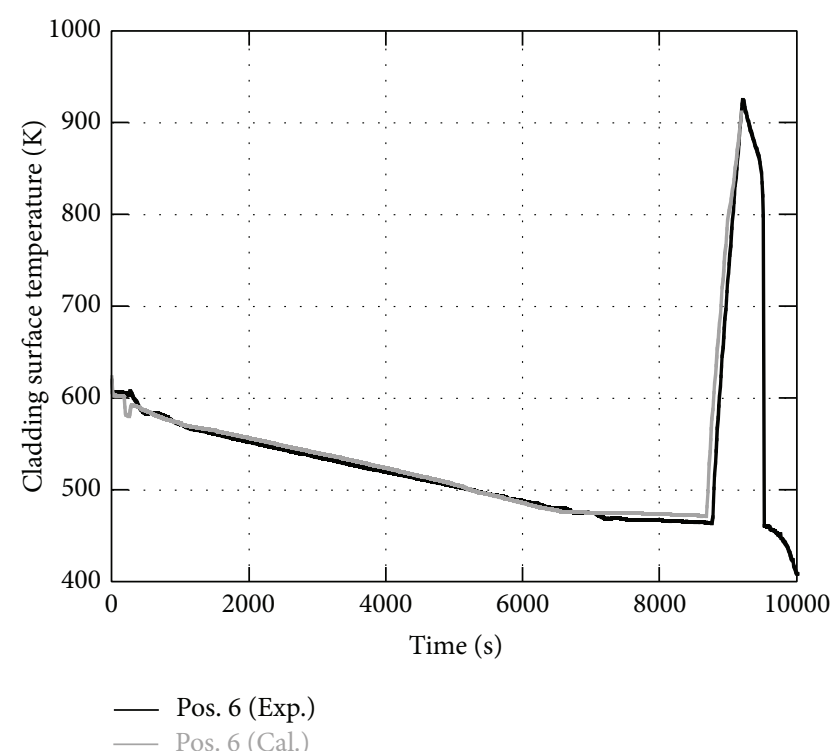

FIGURE 14: LSTF and RELAP5 results for cladding surface temperature under $55 \mathrm{~K} / \mathrm{h}$ rate and $30 \mathrm{~min}$ AFW.

because of influences of the vessel lower plenum fluid flashing due to steam condensation on ACC coolant injected into cold legs. The steam condensation on ACC coolant is calculated by gas-liquid inter-phase heat transfer model depending on the flow regime. In the analysis, the flow regime at the breakupstream piping changed from bubbly flow into stratified flow due to the slip velocity decrease with the start of ACC coolant injection. The stratified flow prevailed afterwards, which caused no oscillation in the break-upstream void fraction. In the SP3 test, on the contrary, some oscillation occurred in the break-upstream void fraction. The liquid level recovery at the upper plenum and core in oscillative manner was not properly simulated because of large discrepancy in the ACC flow rate fluctuation (Figures 11-13). In the analysis only, a large spike appeared in the upper plenum collapsed liquid level during the time period around $5140-5340 \mathrm{~s}$ due to larger ACC flow rate than in the SP3 test (Figures 11 and 12).

The primary pressure was a little overpredicted after the gas inflow (Figure 7). The condensation heat transfer with influences of noncondensable gas is calculated by using the maximum value between the estimations based on the Shah model [29] and on the Nusselt model [30] with the multipliers of the Vierow-Schrock correlation [31]. The multipliers concern the heat transfer degradation expressed as a function of gas mass fraction which includes effects of the interfacial shear and the gas presence in a vertical tube at low pressures. The calculated gas mass fraction showed no accumulation of noncondensable gas in the vessel upperhead probably due to influences of steam at the upper-head by the fluid flashing because of the SG depressurization. A little overprediction of the primary pressure may be caused by underestimation of steam condensation in the SG U-tubes using the condensation heat transfer model under steam-gas mixture condition. The onset timing of core uncovery and 


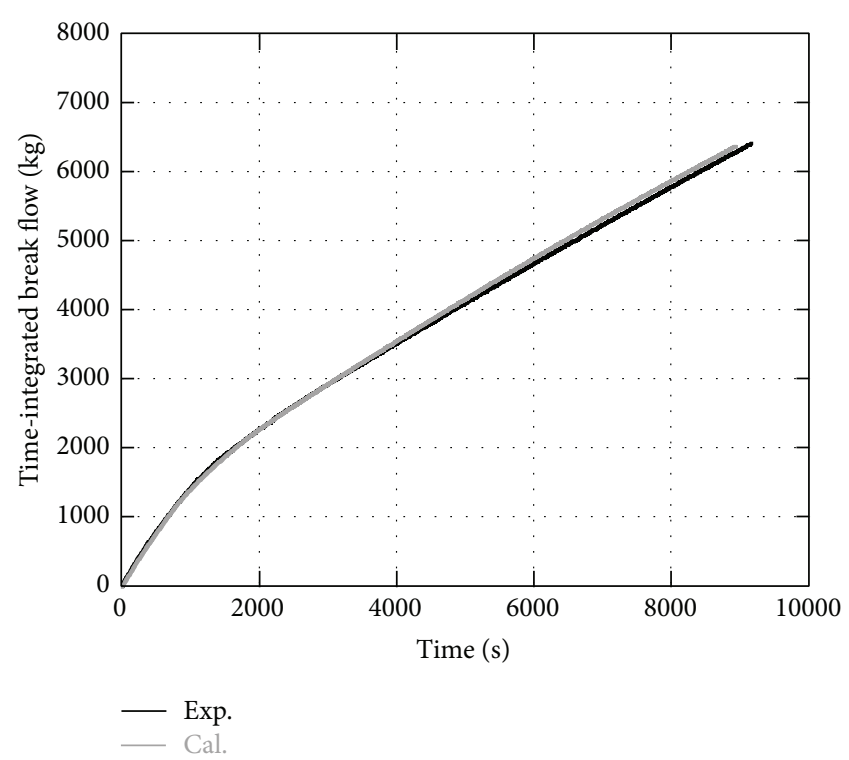

(a) Time-integrated break flow

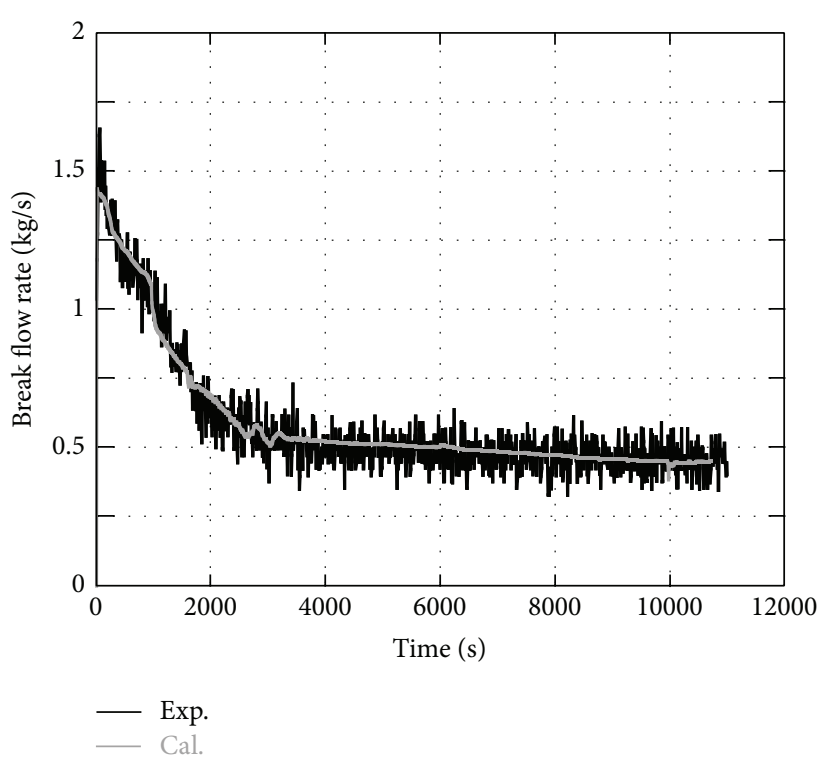

(b) Break flow rate

FIGURE 15: LSTF and RELAP5 results for break flow under full opening of SG RVs and continuous AFW.

heatup was somewhat earlier in the analysis than in the SP3 test (Figures 13 and 14).

\subsection{SP4 Test and RELAP5 Analysis under Full Opening of $S G R V$ s and Continuous AFW Injection}

3.4.1. SP4 Test Conditions. The SG secondary-side depressurization was conducted by fully opening the RVs (inner diameter of $16.2 \mathrm{~mm}$ each) in both SGs. The AFW injection was done into the secondary-side of both SGs continuously. The AFW flow rate was at a constant value of $0.7 \mathrm{~kg} / \mathrm{s}$ for each SG until the SG secondary-side collapsed liquid level reached a certain high level and was controlled to keep the certain high level thereafter.

3.4.2. Major Phenomena Observed in SP4 Test. The chronology of major events in the SP4 test is summarized in Table 3. The primary depressurization following the SG depressurization was faster than in the SP3 test (Figure 17) because of larger discharge rate of steam through the SG valves especially with the start of AM measures, which caused earlier initiation of ACC coolant injection. After the onset of AM measures, the break flow rate became smaller than in the SP3 test (Figure 15) because of faster primary depressurization. Break flow turned from single-phase liquid to two-phase flow at about $1060 \mathrm{~s}$ due to the saturation of the vessel lower plenum fluid and returned to single-phase liquid at about $3680 \mathrm{~s}$. The two-phase break flow duration thus was much shorter than in the SP3 test. The SG secondary-side collapsed liquid level greatly decreased after the SG depressurization and gradually recovered by the AFW injection into the SG secondaryside after around $2000 \mathrm{~s}$ (Figure 18). The SG secondary-side collapsed liquid level reached a certain high level and was kept at the certain high level by controlling the AFW flow rate thereafter. The SG U-tube collapsed liquid level and the primary loop flow rate recovered following recovery of the primary coolant inventory after the initiation of ACC coolant injection (Figures 19-21).

The gas inflow to the primary system started much earlier than in the SP3 test because of much earlier completion of ACC coolant injection. Nonuniform flow behaviors were observed in the SG U-tubes with noncondensable gas ingress (Figure 19) probably depending on the gas accumulation rate in the tubes. The coolant drained in one medium tube (tube 2 in Table 2) of SG in loop-B slower than in other instrumented U-tubes. During the time period around 6500-7500 s, the SG U-tube collapsed liquid level temporarily increased due to a small increase in the primary pressure. After the gas inflow, the primary loop flow rate gradually decreased under twophase NC (Figure 20). The two-phase NC terminated because of adverse heat transfer around the top portion of the SG U-tubes, which emerged above the two-phase mixture level. The LPI system was actuated with no core heatup because of smaller loss rate of the primary coolant inventory than in the SP3 test and adequate heat removal by the SGs (Figures 21 and 24). Significant drop occurred in the upper plenum collapsed liquid level just before the LPI actuation following depletion of the primary coolant inventory after the termination of ACC coolant injection (Figure 22). A temporal and small decrease appeared in the core collapsed liquid level because of steam condensation on LPI coolant injected into the cold legs. The collapsed liquid levels recovered at the upper plenum and core thereafter.

3.4.3. Comparison of Calculated Results with SP4 Test Data. The RELAP5 code predicted well the overall trend of thermalhydraulic response observed in the SP4 test, as shown in 


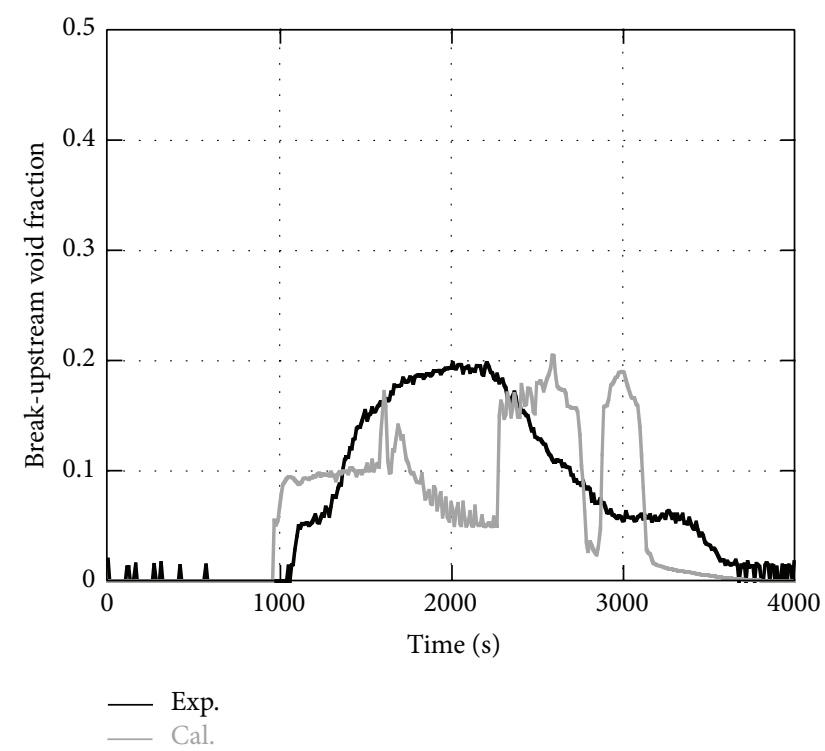

FIGURE 16: LSTF and RELAP5 results for void fraction at breakupstream piping under full opening of SG RVs and continuous AFW.

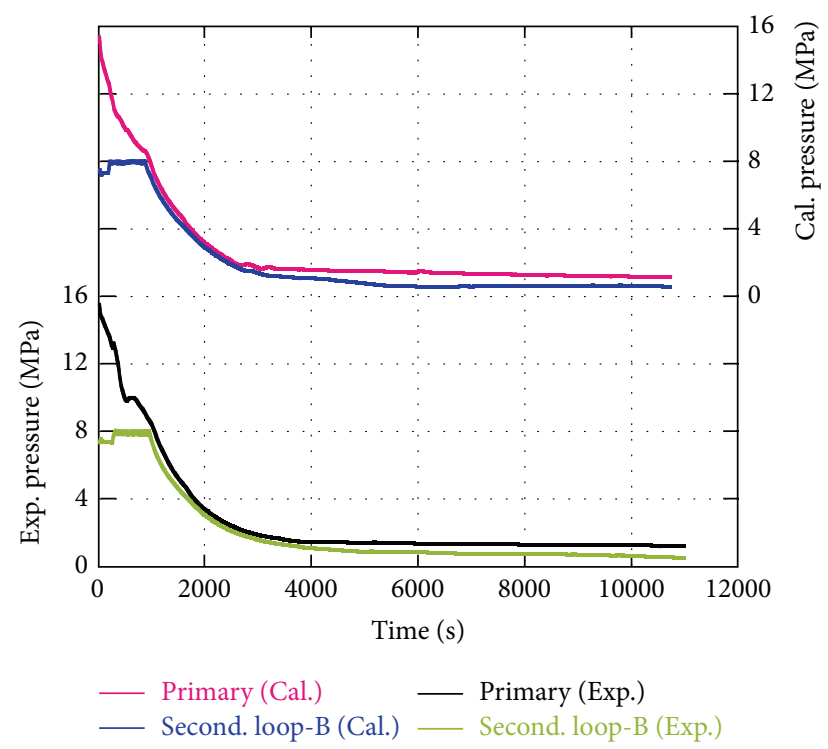

FIGURE 17: LSTF and RELAP5 results for primary and SG secondary pressures under full opening of SG RVs and continuous AFW.

Figures 15-24. The posttest analysis was terminated when the LPI system is actuated.

The code calculated the SG secondary-side collapsed liquid level reasonably well (Figure 18). The break flow rate was a bit overpredicted during two-phase flow discharge period partly due to underprediction of void fraction at the breakupstream piping (Figures 15 and 16). Such overprediction of the break flow rate may suggest that the adjustment of a discharge coefficient for two-phase discharge flow would be needed when the built-in critical flow model [18] in the RELAP5 code is employed. In the analysis, the flow regime at the break-upstream piping changed from bubbly flow into

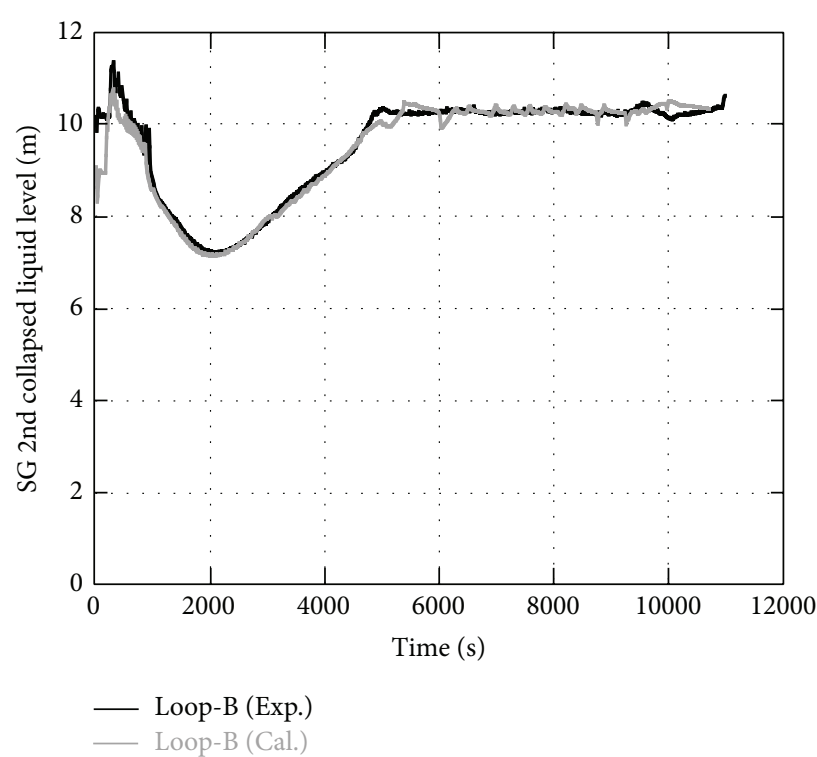

FIGURE 18: LSTF and RELAP5 results for SG secondary-side collapsed liquid level under full opening of SG RVs and continuous AFW.

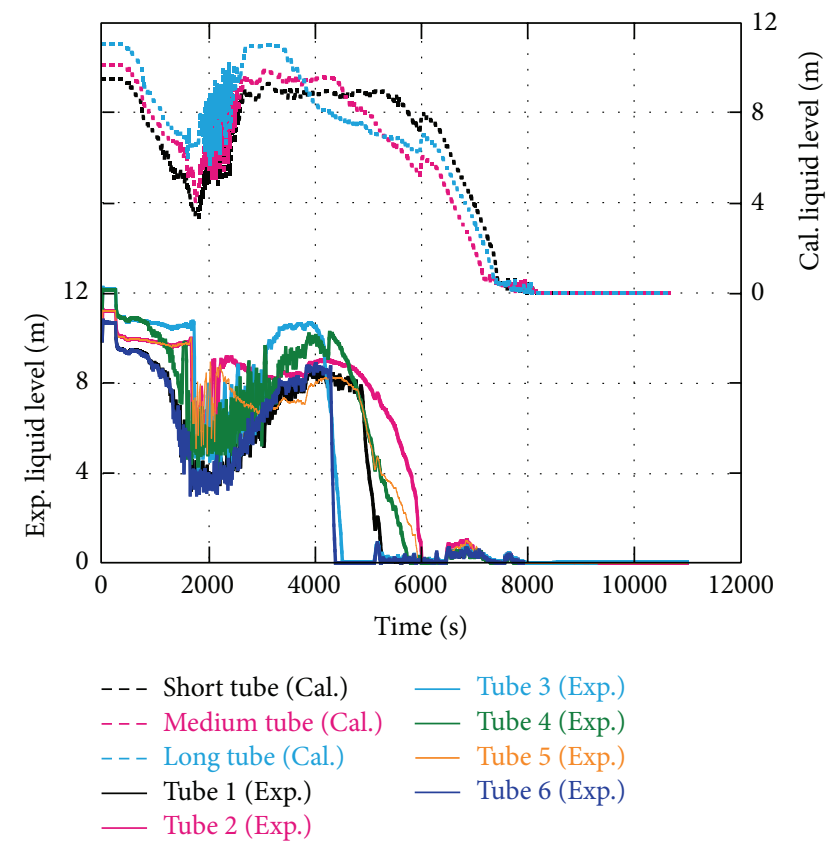

FIGURE 19: LSTF and RELAP5 results for SG-B U-tube upflow side collapsed liquid level under full opening of SG RVs and continuous AFW.

stratified flow with the start of ACC coolant injection. The stratified flow prevailed until the termination of ACC coolant injection, which caused no oscillation in the break-upstream void fraction similar to that in the SP4 test. In the analysis only, significant fluctuation appeared in the ACC flow rate (Figure 21) due to influences of steam condensation in the cold leg volume where fluctuation occurred in the pressure, which affected the void fraction at the break-upstream piping (Figure 16). The significant fluctuation in the ACC flow 


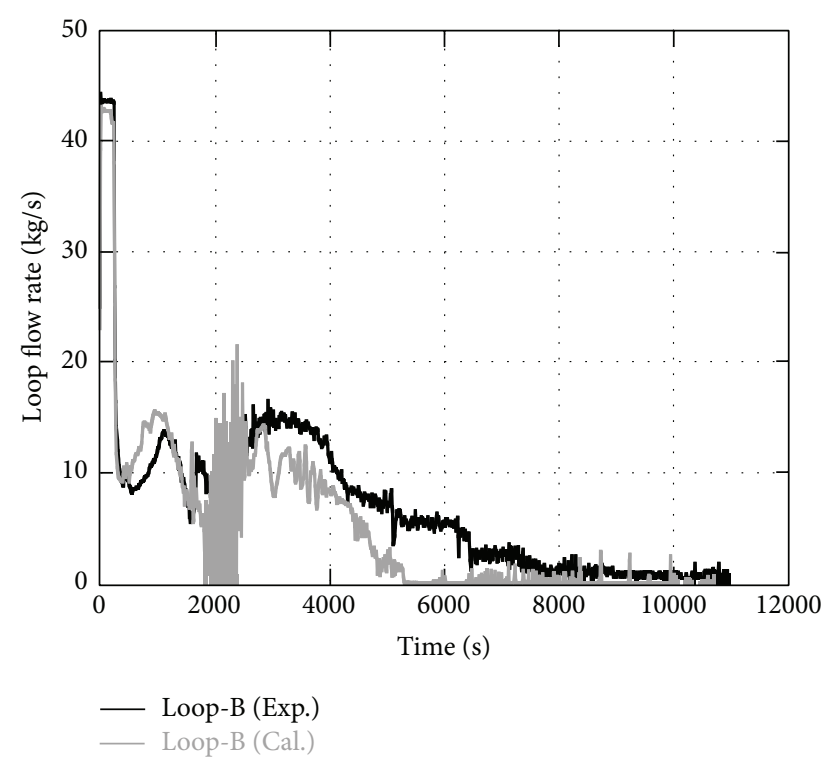

Figure 20: LSTF and RELAP5 results for primary loop flow rate under full opening of SG RVs and continuous AFW.

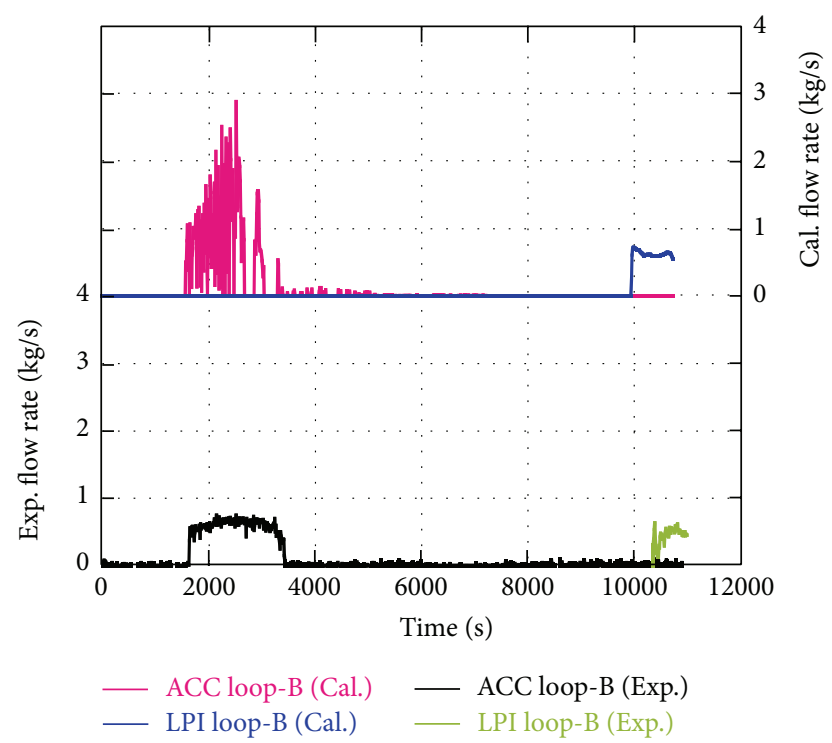

FIGURE 21: LSTF and RELAP5 results for accumulator and low pressure injection flow rate under full opening of SG RVs and continuous AFW.

rate caused larger fluctuation in the primary loop flow rate (Figure 20) and in the collapsed liquid levels at the upper plenum and core (Figures 22 and 23) than in the SP4 test.

As a result of the calculated gas mass fraction, there was no accumulation of noncondensable gas in the vessel upper-head similar to the calculated result of the SP3 test. A little overprediction of the primary pressure after the gas inflow (Figure 17) may be caused by underestimation of steam condensation in the SG U-tubes. The SG U-tube collapsed liquid level was roughly predicted, though with a tendency

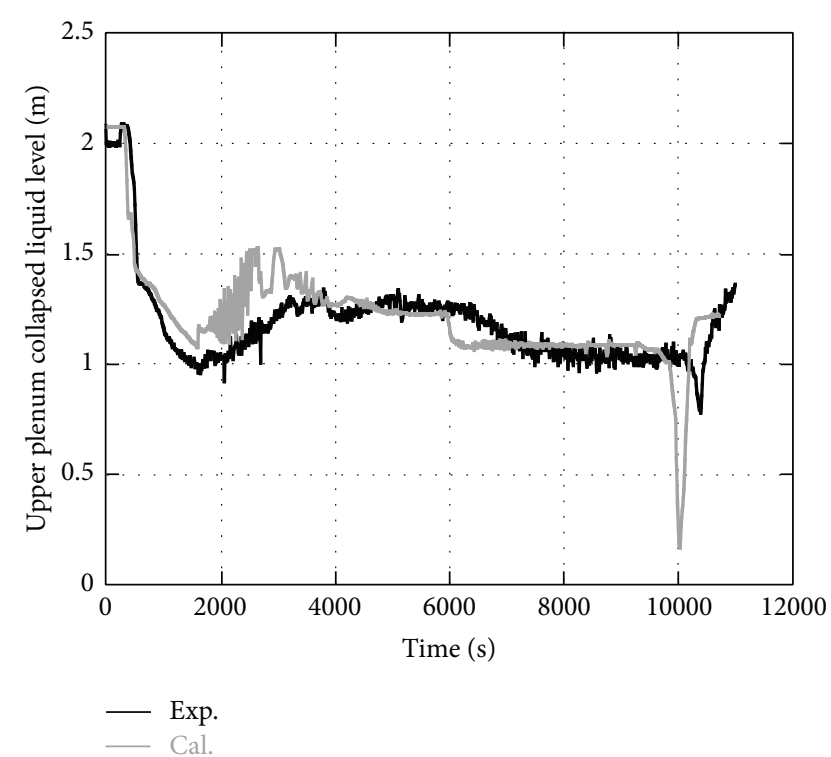

FIGURE 22: LSTF and RELAP5 results for upper plenum collapsed liquid level under full opening of SG RVs and continuous AFW.

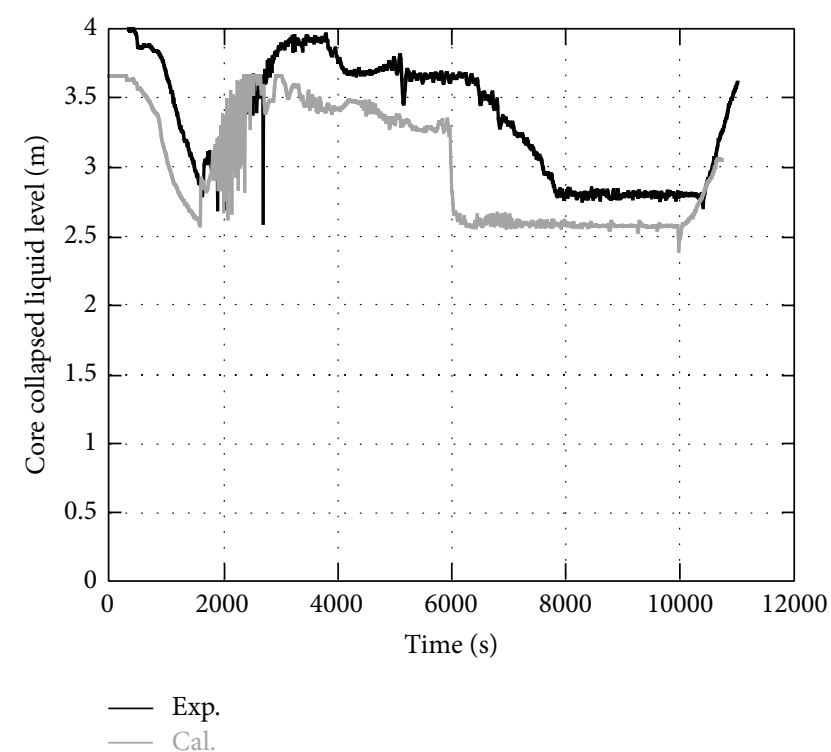

FIGURE 23: LSTF and RELAP5 results for core collapsed liquid level under full opening of SG RVs and continuous AFW.

that the coolant drained rather slower than in the SP4 test probably due to influences of the gas accumulation rate in the tubes (Figure 19). Two-phase NC terminated earlier in the analysis than in the SP4 test because the primary loop flow rate decreased to zero earlier (Figure 20). The drop in the upper plenum collapsed liquid level just before the LPI actuation was more significant in the analysis than in the SP4 test because of a bit overprediction of the break flow rate (Figure 22). The code reproduced no core uncovery and heatup because of reasonably well prediction of the core collapsed liquid level (Figures 23 and 24). 


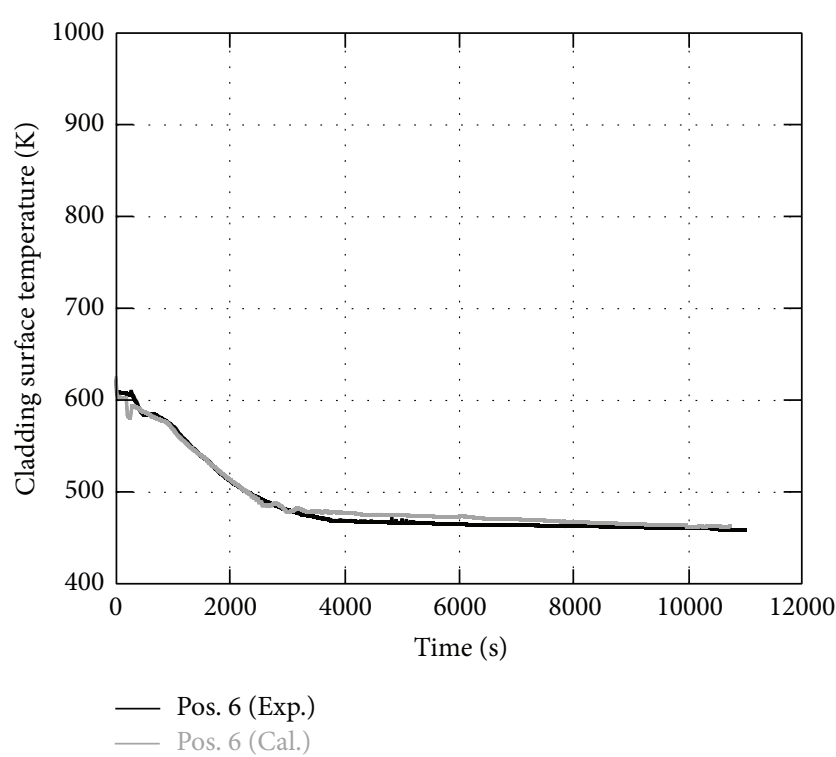

FIGURE 24: LSTF and RELAP5 results for cladding surface temperature under full opening of SG RVs and continuous AFW.

\section{Discussion}

4.1. Influences of Timing on Full Opening of SG RVs onto LongTerm Core Cooling. Influences of timing on the full opening of the SG RVs onto long-term core cooling were investigated through comparison of results of the three LSTF tests. The major test conditions and the chronology of major events in the SP6 test are shown in Tables 1 and 3, respectively. The (first) SG depressurization and AFW injection were initiated 10 min after the safety injection signal. The SG depressurization rate was controlled by means of steam discharge through the flow control valves at both SGs to achieve the primary depressurization rate of $55 \mathrm{~K} / \mathrm{h}$ until $4550 \mathrm{~s}$ when the pressure vessel liquid level became below the hot leg level first, and then the RVs in both SGs were fully opened as the second SG depressurization. The AFW flow rate was planned to decrease to a certain small flow rate in several steps following the SG secondary-side pressure decrease after $2100 \mathrm{~s}$. The AFW injection, however, was terminated at $6720 \mathrm{~s}$ because the operation of AFW pumps was forcedly stopped due to unexpected noise generated from the pumps. In the SP3 test, on the contrary, the primary depressurization rate was kept at $55 \mathrm{~K} / \mathrm{h}$ with the AFW injection for $30 \mathrm{~min}$.

Figures 25-28 compare major results of the SP6 test with the SP3 test. During the time period around 2100-3200 s, the SG secondary-side collapsed liquid level became lower in the SP6 test than in the SP3 test because of smaller AFW flow rate (Figure 26). In the SP6 test, the full opening of the SG RVs enhanced decreases in the primary pressure and in the SG secondary-side collapsed liquid level (Figures 25 and 26). The enhanced primary depressurization caused a quick recovery of the core liquid level (Figure 27). At the onset of core uncovery by boil-off, the SG secondary-side collapsed liquid level remained at $5.5 \mathrm{~m}$ in the SP6 test which was higher than $1.2 \mathrm{~m}$ in the SP3 test because of longer AFW injection.

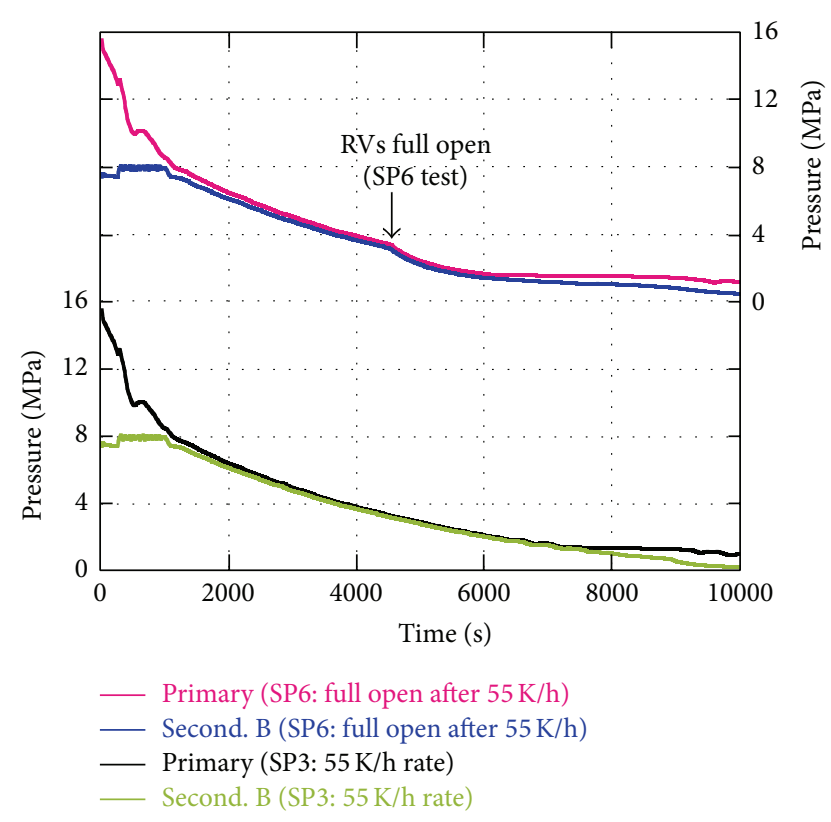

FIGURE 25: Influences of timing on full opening of SG RVs onto primary and SG secondary pressures by LSTF tests.

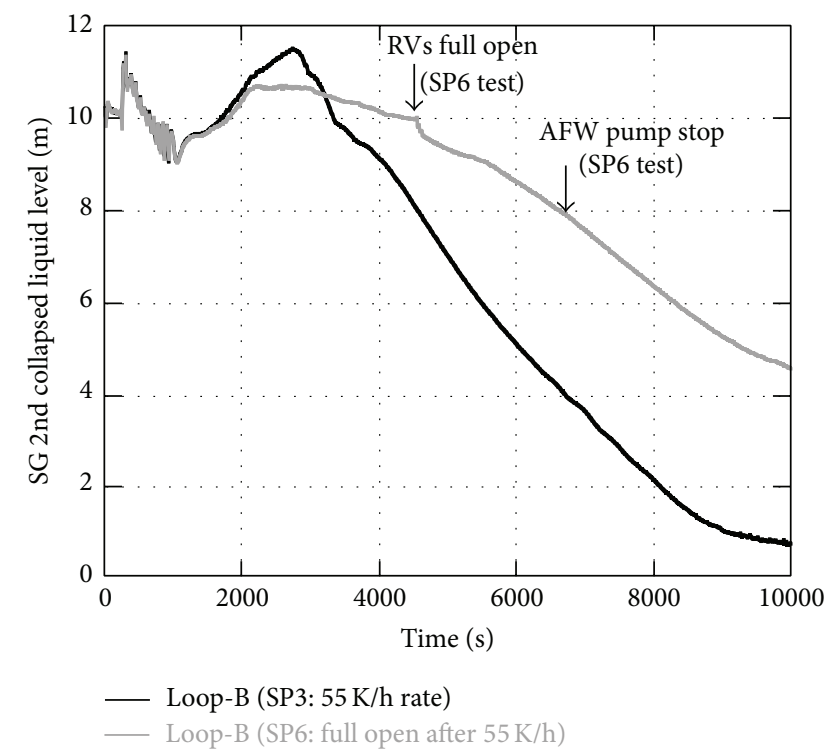

FIGURE 26: Influences of timing on full opening of SG RVs onto SG secondary-side collapsed liquid level by LSTF tests.

The onset timing of core uncovery and heatup before the LPI actuation in the SP6 test was almost the same as in the SP3 test (Figure 28). The peak cladding temperature was observed at Position 7 (= about $0.8 \mathrm{~m}$ above the core center) in the SP6 test but at Position 6 (= about $0.4 \mathrm{~m}$ above the core center) in the SP3 test. The peak cladding temperature was higher in the SP6 test than in the SP3 test because of later LPI actuation after the automatic core power reduction shown in Table 3. In the SP6 test, the full opening of the SG RVs as the second SG depressurization was ineffective to the core cooling. 


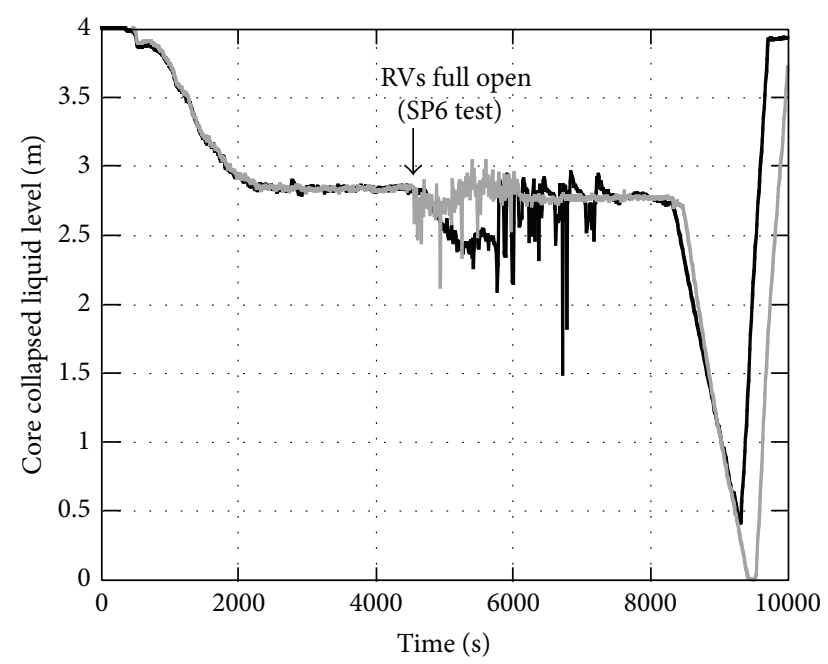

— SP3: $55 \mathrm{~K} / \mathrm{h}$ rate

_ SP6: full open after $55 \mathrm{~K} / \mathrm{h}$

FIGURE 27: Influences of timing on full opening of SG RV s onto core collapsed liquid level by LSTF tests.

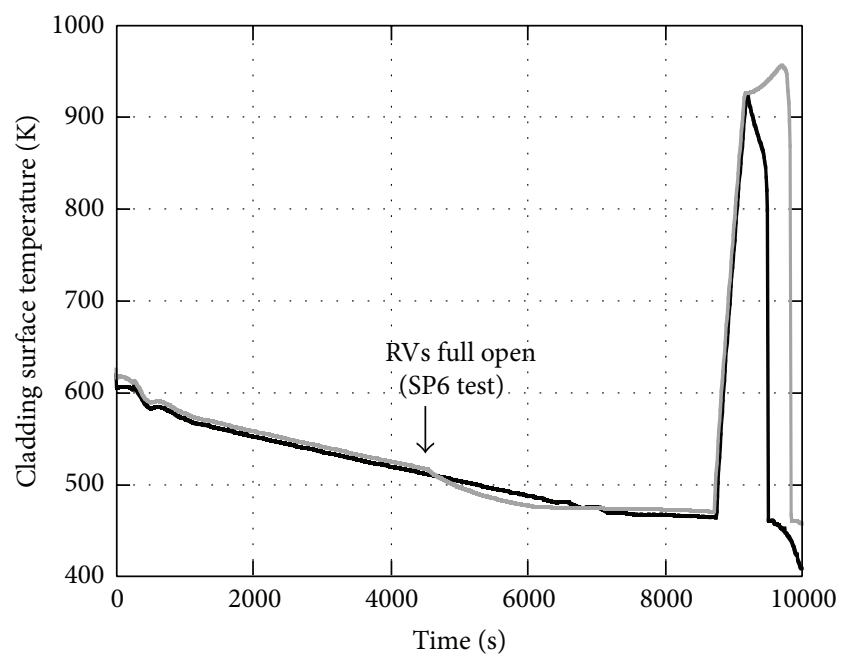

— Pos. 6 (SP3: $55 \mathrm{~K} / \mathrm{h}$ rate)

— Pos. 7 (SP6: full open after 55k/h)

FIGURE 28: Influences of timing on full opening of SG RVs onto cladding surface temperature by LSTF tests.

In the SP4 test, on the contrary, no core uncovery and heatup occurred when the full opening of the SG RVs was initiated $10 \mathrm{~min}$ after the safety injection signal, as shown in Figures 23 and 24. Timing on the full opening of the SG RVs thus influenced the long-term core cooling significantly.

4.2. Influences of Primary Depressurization Rate onto LongTerm Core Cooling. Influences of the primary depressurization rate through the SG depressurization with continuous AFW injection onto long-term core cooling were investigated

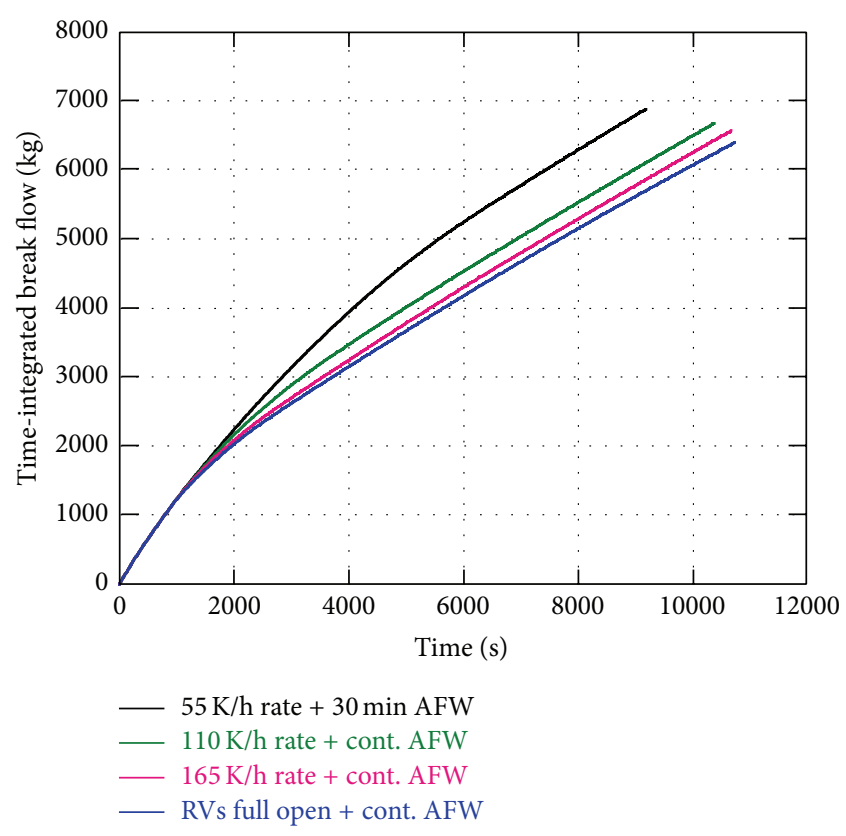

FIGURE 29: Influences of primary depressurization rate onto timeintegrated break flow by RELAP5 analyses.

by sensitivity analyses, based on the RELAP5 posttest analyses on the SP3 and SP4 tests. Employed analysis models were the same as those for the posttest analyses. The SG depressurization and AFW injection as the AM measures were assumed to start $10 \mathrm{~min}$ after the safety injection signal, which are the same as in the SP3 and SP4 tests. The assumed primary depressurization rates were 110 and $165 \mathrm{~K} / \mathrm{h}$ respectively that correspond to twice and three times as large as $55 \mathrm{~K} / \mathrm{h}$ of the SP3 test condition, considering flow capacities of the SG valves. The continuous AFW injection was assumed in the same manner as the SP4 test to achieve adequate SG heat removal.

Figures 29-32 show major results of the sensitivity analyses, being compared with those of the posttest analyses on the SP3 and SP4 tests. The time-integrated break flow was smaller as the primary depressurization rate is larger (Figures 29 and 30). The time-integrated break flow was larger in the $165 \mathrm{~K} / \mathrm{h}$ rate case than in the case of the full opening of the SG RVs because of slower primary depressurization. Similar to the $55 \mathrm{~K} / \mathrm{h}$ rate case, therefore, core uncovery and heatup happened before the LPI actuation in the 110 and $165 \mathrm{~K} / \mathrm{h}$ rate cases (Figures 31 and 32). The primary pressure just before the core uncovery and heatup was lower in the $165 \mathrm{~K} / \mathrm{h}$ rate case than in the $55 \mathrm{~K} / \mathrm{h}$ rate case because of later core uncovery and heatup. Loss of the primary coolant inventory depends on the time-integrated break flow. The SG heat removal is influenced by the SG secondary-side collapsed liquid level depending on the AFW injection condition. The influences of the time-integrated break flow as well as the SG secondary-side collapsed liquid level were significant for the primary pressure transients that control the LPI actuation in such vessel bottom SBLOCA with AM measures under noncondensable gas inflow. 


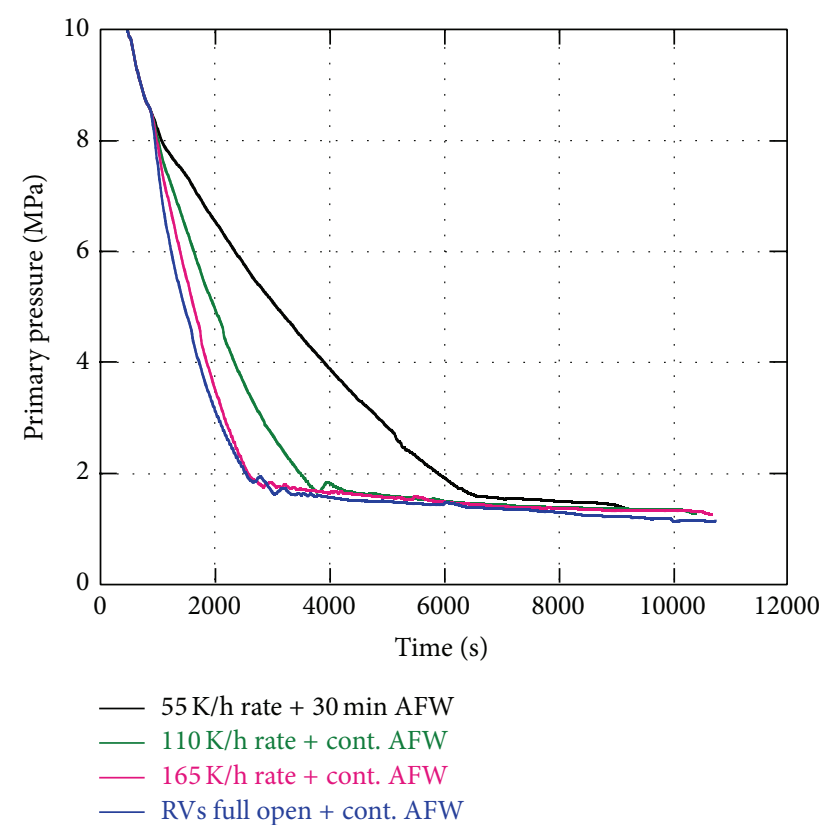

FIGURE 30: Influences of primary depressurization rate onto primary pressure by RELAP5 analyses.

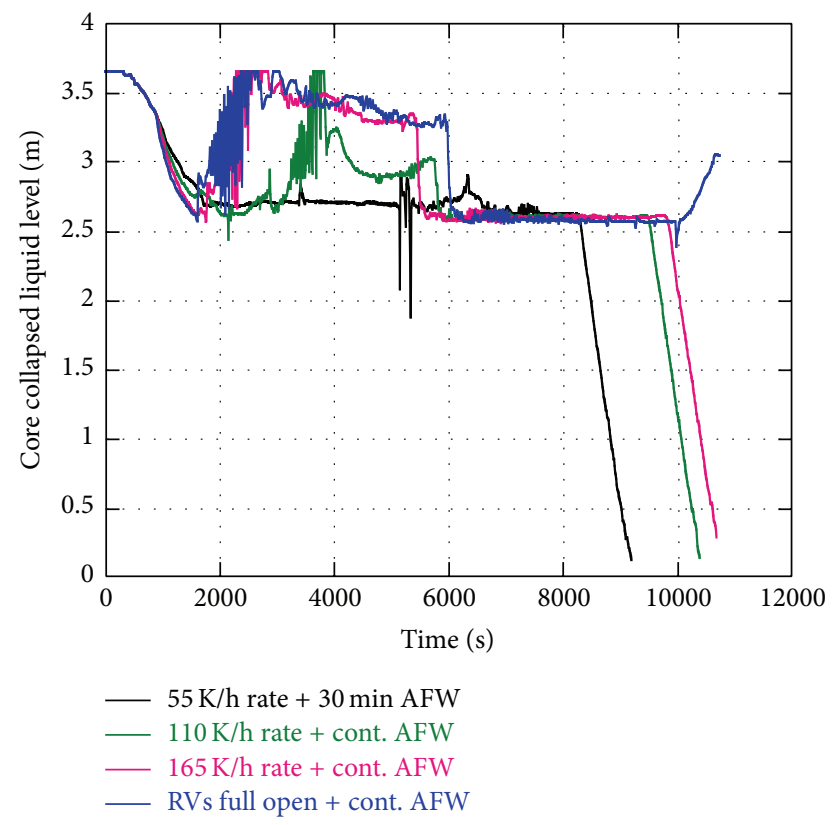

FIGURE 31: Influences of primary depressurization rate onto core collapsed liquid level by RELAP5 analyses.

\subsection{Identifications of High-Ranked Phenomena and Relevant}

Key Parameters. Precise prediction of the core liquid level behavior and thus the cladding surface temperature is essential for the realistic evaluation of safety margin at PWR vessel bottom SBLOCA with AM measures under noncondensable gas inflow. Thermal-hydraulic phenomena defined as highranked phenomena may affect the cladding surface temperature significantly [32]. Identifications of the high-ranked

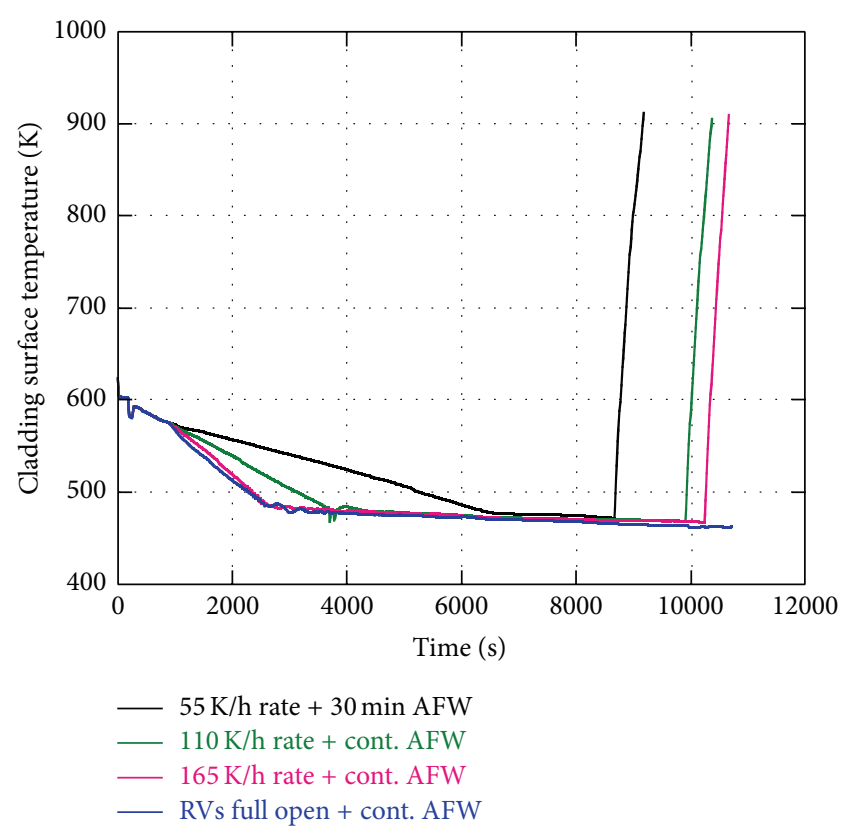

FIGURE 32: Influences of primary depressurization rate onto cladding surface temperature by RELAP5 analyses.

phenomena and relevant key parameters were conducted based on the RELAP5 post-test analyses of the LSTF tests, referring to the ranking of PWR SBLOCA phenomena [33].

Table 4 shows the high-ranked phenomena identified. Such high-ranked phenomena as critical flow through the break and steam condensation in the SG U-tubes under the gas accumulation concern the predictions of break flow rate and primary pressure after the gas inflow, respectively, as the code's remaining problems. Other high-ranked phenomena are described below. Core power after a scram signal is based on decay heat from the fuel rods. The cladding surface temperature rises when the rod surface is uncovered above twophase mixture level in the core. Steam condensation on ACC or LPI coolant injected into the cold legs causes a temporal and small decrease in the core collapsed liquid level. Steam discharge through the SG valves for the depressurization leads to steam condensation in the SG U-tubes to cool and depressurize the primary system.

As shown in Table 4, identified key parameters related to the high-ranked phenomena include discharge coefficients through the break and the SG valves, core decay power, gasliquid inter-phase drag in the core, gas-liquid inter-phase heat transfer in the cold legs, and condensation heat transfer in the SG U-tubes under steam-gas mixture condition. Calculated results by best-estimate computer codes (e.g., RELAP5 code) include uncertainties especially in boundary conditions and physical models. The core decay power and the other key parameters are associated with the boundary condition and the physical models, respectively. Analyses of the LSTF test on the vessel bottom SBLOCA with AM measures under the gas inflow by using best-estimate plus uncertainty methods [34] may be the next step. The key parameters above would 
TABLE 4: High-ranked phenomena and relevant key parameters identified.

\begin{tabular}{|c|c|c|}
\hline Component & Phenomenon & Parameter \\
\hline Break & Critical flow & $\begin{array}{l}\text { Discharge } \\
\text { coefficient } \\
\text { through break }\end{array}$ \\
\hline Fuel rods & Decay heat & Core decay power \\
\hline Core & $\begin{array}{l}\text { Two-phase } \\
\text { mixture level }\end{array}$ & $\begin{array}{l}\text { Gas-liquid } \\
\text { inter-phase drag } \\
\text { in core }\end{array}$ \\
\hline $\begin{array}{l}\text { Cold legs/ACC } \\
\text { or LPI system }\end{array}$ & $\begin{array}{c}\text { Steam } \\
\text { condensation } \\
\text { on ACC or } \\
\text { LPI coolant }\end{array}$ & $\begin{array}{l}\text { Gas-liquid } \\
\text { inter-phase heat } \\
\text { transfer in cold } \\
\text { legs }\end{array}$ \\
\hline SG U-tubes & $\begin{array}{c}\text { Steam } \\
\text { condensation } \\
\text { under non- } \\
\text { condensable } \\
\text { gas } \\
\text { accumulation }\end{array}$ & $\begin{array}{l}\text { Condensation } \\
\text { heat transfer in } \\
\text { SG U-tubes } \\
\text { under steam-gas } \\
\text { mixture } \\
\text { condition }\end{array}$ \\
\hline $\begin{array}{l}\text { SG valves for } \\
\text { depressurization }\end{array}$ & $\begin{array}{l}\text { Steam } \\
\text { discharge }\end{array}$ & $\begin{array}{l}\text { Discharge } \\
\text { coefficient } \\
\text { through SG } \\
\text { valves }\end{array}$ \\
\hline
\end{tabular}

then be important uncertainty parameters, which may affect the cladding surface temperature significantly.

\section{Conclusions}

RELAP5 code posttest analyses were performed on ROSA/ LSTF experiments simulating PWR $0.2 \%$ vessel bottom SBLOCAs with different AM measures under assumptions of noncondensable gas inflow and total failure of HPI system. Depressurization of and AFW injection into the secondaryside of both SGs as the AM measures were taken $10 \mathrm{~min}$ after a safety injection signal. Sensitivity analyses were conducted further to investigate influences of the primary depressurization rate through the SG depressurization with continuous AFW injection onto long-term core cooling. Major results are summarized as follows.

(1) The LSTF tests showed the primary depressurization was obstructed due to the gas accumulation in the SG U-tubes after the completion of ACC coolant injection. When the primary pressurization rate became $55 \mathrm{~K} / \mathrm{h}$, core temperature excursion took place by core boil-off before the actuation of LPI system due to rather slow primary depressurization. When the fast primary depressurization was conducted by fully opening the SG RVs with continuous AFW injection, long-term core cooling was ensured by the LPI actuation due to smaller loss rate of the primary coolant inventory and adequate heat removal by the SGs.

(2) The RELAP5 code predicted well the overall trend of thermal-hydraulic response observed in the LSTF tests. The break flow rate, however, was somewhat overpredicted during two-phase flow discharge period partly due to underprediction of void fraction at the break-upstream piping. A little overprediction of the primary pressure after the gas inflow may be caused by underestimation of steam condensation in the SG U-tubes.

(3) It was confirmed that timing on the full opening of the SG RVs affects the long-term core cooling significantly through comparison of the LSTF test results. The sensitivity analyses indicated that core uncovery and heatup would happen before the LPI actuation if the primary depressurization rates are twice and three times as large as $55 \mathrm{~K} / \mathrm{h}$ even when the AFW injection is done into the secondary-side of both SGs continuously. High-ranked phenomena and relevant key parameters were identified based on the RELAP5 posttest analyses of the LSTF tests.

\section{Nomenclature}

$\begin{array}{ll}\text { ACC: } & \text { Accumulator } \\ \text { AFW: } & \text { Auxiliary feedwater } \\ \text { AM: } & \text { Accident management } \\ \text { ECCS: } & \text { Emergency core cooling system } \\ \text { HPI: } & \text { High-pressure injection } \\ \text { LPI: } & \text { Low-pressure injection } \\ \text { LSTF: } & \text { Large scale test facility } \\ \text { NC: } & \text { Natural circulation } \\ \text { PWR: } & \text { Pressurized water reactor } \\ \text { ROSA: } & \text { Rig of safety assessment } \\ \text { RV: } & \text { Relief valve } \\ \text { SBLOCA: } & \text { Small-break loss-of-coolant accident } \\ \text { SG: } & \text { Steam generator. }\end{array}$

\section{Conflict of Interests}

The author declares that there is no conflict of interests regarding the publication of this paper.

\section{Acknowledgments}

The author would like to thank Messrs. M. Ogawa and A. Ohwada of Japan Atomic Energy Agency for performing the LSTF tests under collaboration with members from Nuclear Engineering Co. as well as Miss K. Toyoda of IX Knowledge Inc. for manipulating the test data. The author is grateful to Drs. H. Nakamura and T. Yonomoto of Japan Atomic Energy Agency for their useful comments.

\section{References}

[1] USNRC, "Leakage from Reactor Pressure Vessel Lower Head Penetrations and Reactor Coolant Pressure Boundary Integrity," Bulletin 2003-02, OMB Control 3150-0012, 2003.

[2] C. D. Fletcher and M. A. Bolander, "Analysis of instrument tube ruptures in the Zion-1 pressurized water reactor," Nuclear Technology, vol. 81, no. 1, pp. 52-62, 1988. 
[3] Y. Kukita, H. Asaka, H. Nakamura, and K. Tasaka, "Pressurized water reactor core instrument tube ruptures: experimental simulation at the ROSA-IV LSTF," Nuclear Engineering and Design, vol. 120, no. 2-3, pp. 249-257, 1990.

[4] Y. Kukita, K. Tasaka, H. Asaka, T. Yonomoto, and H. Kumamaru, "The effects of break location on PWR small break LOCA: experimental study at the ROSA-IV LSTF," Nuclear Engineering and Design, vol. 122, no. 1-3, pp. 255-262, 1990.

[5] The ROSA-V Group, "ROSA-V large scale test facility (LSTF) system description for the third and fourth simulated fuel assemblies," JAERI-Tech 2003-037, Japan Atomic Energy Research Institute, Ibaraki, Japan, 2003.

[6] H. Asaka and Y. Kukita, "Intentional depressurization of steam generator secondary side during a PWR small-break loss-ofcoolant accident," Journal of Nuclear Science and Technology, vol. 32, no. 2, pp. 101-110, 1995.

[7] G. G. Loomis, "Summary of the Semiscale program (19651986),” USNRC Report NUREG/CR-4945, EGG-2509, 1987.

[8] C. Addabbo and A. Annunziato, "The LOBI integral system test facility experimental programme," Science and Technology of Nuclear Installations, vol. 2012, Article ID 238019, 16 pages, 2012.

[9] K. Umminger, L. Dennhardt, S. Schollenberger, and B. Schoen, "Integral test facility PKL: experimental PWR accident investigation," Science and Technology of Nuclear Installations, vol. 2012, Article ID 891056, 16 pages, 2012.

[10] H. Asaka, Y. Anoda, Y. Kukita, and I. Ohtsu, "Secondaryside depressurization during PWR cold-leg small break LOCAs based on ROSA-V/LSTF experiments and analyses," Journal of Nuclear Science and Technology, vol. 35, no. 12, pp. 905-915, 1998.

[11] T. Takeda, A. Ohwada, and H. Nakamura, "Measurement of non-condensable gas in a PWR small-break LOCA simulation test with LSTF for OECD/NEA ROSA Project and RELAP5 post-test analysis," Experimental Thermal and Fluid Science, vol. 51, pp. 112-121, 2013.

[12] H. Nakamura, T. Watanabe, T. Takeda et al., "RELAP5/MOD3 code verification through PWR pressure vessel small break loca tests in OECD/NEA ROSA project," in Proceedings of the 16th International Conference on Nuclear Engineering (ICONE16 '08), pp. 659-668, Orlando, Fla, USA, May 2008.

[13] H. Nakamura, T. Watanabe, T. Takeda, Y. Maruyama, and M. Suzuki, "Overview of recent efforts through ROSA/LSTF experiments," Nuclear Engineering and Technology, vol. 41, no. 6, pp. 753-764, 2009.

[14] H. Asaka and Y. Anoda, "Study of accident management measures for prevention of severe core damage in ROSA-V program," Japanese Journal of Multiphase Flow, vol. 17, no. 2, pp. 116-125, 2003 (Japanese).

[15] M. Suzuki, T. Takeda, H. Asaka, and H. Nakamura, "Experimental study on secondary depressurization action for PWR vessel bottom small break LOCA with HPI failure and gas inflow (ROSA-V/LSTF Test SB-PV-03)," JAERI-Research 2005014, Japan Atomic Energy Research Institute, Ibaraki, Japan, 2005.

[16] M. Suzuki, T. Takeda, H. Asaka, and H. Nakamura, "An experimental study on effective depressurization actions for PWR vessel bottom break LOCA with HPI failure and gas inflow (ROSAV/LSTF Test SB-PV-04)," JAEA-Research 2006-018, Japan Atomic Energy Agency, Ibaraki, Japan, 2006.

[17] M. Suzuki, T. Takeda, H. Asaka, and H. Nakamura, "A study on timing of rapid depressurization action during PWR vessel bottom break LOCA with HPI failure and AIS-gas inflow (ROSA-V/LSTF test SB-PV-06)," JAEA-Research-2007037, Japan Atomic Energy Agency, Ibaraki, Japan, 2007.

[18] RELAP5 Code Development Team, "RELAP5/MOD3 code manual," Tech. Rep. NUREG/CR-5535 (INEL-95/0174), Idaho National Engineering Laboratory, 1995.

[19] M. Suzuki, T. Takeda, H. Asaka, and H. Nakamura, "Effects of secondary depressurization on core cooling in PWR vessel bottom small break LOCA experiments with HPI failure and gas inflow," Journal of Nuclear Science and Technology, vol. 43, no. 1, pp. 55-64, 2006.

[20] T. Takeda, T. Watanabe, and H. Nakamura, "Effectiveness of AM measures for long-term core cooling during PWR vessel bottom small-break LOCA based on RELAP5 analyses of ROSA/LSTF experiment," in Proceedings of the 9th International Topical Meeting on Nuclear Thermal-Hydraulics, Operation and Safety (NUTHOS-9 '12), Kaohsiung, Taiwan, September 2012.

[21] N. Zuber, "Problems in modeling small break LOCA," USNRC Report NUREG-0724, 1980.

[22] H. Kumamaru and K. Tasaka, "Recalculation of simulated post-scram core power decay curve for use in ROSA-IV/LSTF experiments on PWR small-break LOCAs and transients," Tech. Rep. JAERI-M 90-142, Japan Atomic Energy Research Institute, Ibaraki, Japan, 1990.

[23] H. Asaka, Y. Kukita, T. Yonomoto, Y. Koizumi, and K. Tasaka, "Results of $0.5 \%$ cold-leg small-break LOCA experiments at ROSA-IV/LSTF: effect of break orientation," Experimental Thermal and Fluid Science, vol. 3, no. 6, pp. 588-596, 1990.

[24] H. K. Fauske, "The discharge of saturated water through tubes," Chemical Engineering and Progress Symposium Series, vol. 61, no. 59, pp. 210-216, 1965.

[25] K. H. Ardron and R. A. Furness, "A study of the critical flow models used in reactor blowdown analysis," Nuclear Engineering and Design, vol. 39, no. 2-3, pp. 257-266, 1976.

[26] D. W. Sallet, “Thermal hydraulics of valves for nuclear applications," Nuclear Science and Engineering, vol. 88, no. 3, pp. 220244, 1984.

[27] Susyadi and T. Yonomoto, "Analysis on non uniform flow in steam generator during steady state natural circulation cooling," JAERI- Research 2005-011, Japan Atomic Energy Research Institute, Ibaraki, Japan, 2005.

[28] T. Takeda, H. Asaka, and H. Nakamura, "RELAP5 analysis of OECD/NEA ROSA project experiment simulating a PWR lossof-feedwater transient with high-power natural circulation," Science and Technology of Nuclear Installations, vol. 2012, Article ID 957285, 15 pages, 2012.

[29] M. M. Shah, "A general correlation for heat transfer during film condensation inside pipes," International Journal of Heat and Mass Transfer, vol. 22, no. 4, pp. 547-556, 1979.

[30] W. A. Nusselt, "The surface condensation of water vapor," Zeitschrift des Vereines Deutscher Ingenieure, vol. 60, pp. 541546, 1916.

[31] K. M. Vierow and V. E Schrock, "Condensation in a natural circulation loop with non-condensable gases part I-heat transfer," in Proceedings of International Conference on Multiphase Flows, Ibaraki, Japan, September 1991.

[32] G. E. Wilson and B. E. Boyack, "The role of the PIRT process in experiments, code development and code applications associated with reactor safety analysis," Nuclear Engineering and Design, vol. 186, no. 1-2, pp. 23-37, 1998. 
[33] B. E. Boyack and L. W. Ward, "Validation test matrix for the consolidated TRAC (TRAC-M) code," in Proceedings of the International Meeting on Best Estimate Methods in Nuclear Installation Safety Analysis (BE '00), Washington, Wash, USA, November 2000.

[34] A. Yamaguchi, S. Mizokami, Y. Kudo, and A. Hotta, "Uncertainty and conservatism in safety evaluations based on a BEPU approach," in Proceedings of the 13th International Topical Meeting on Nuclear Reactor Thermal Hydraulics (NURETH-13 '09), Ishikawa, Japan, September-October 2009. 


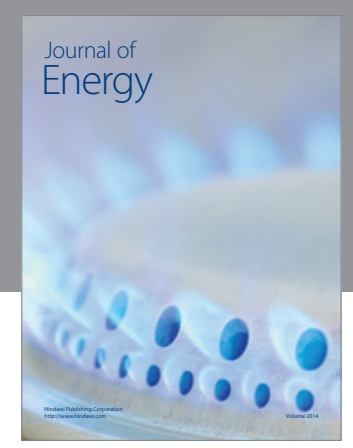

Journal of

Industrial Engineering
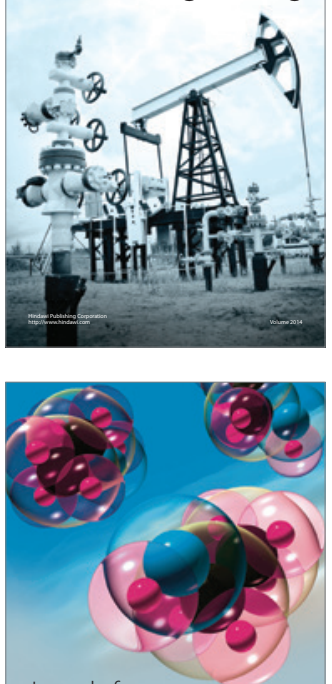

Fuels
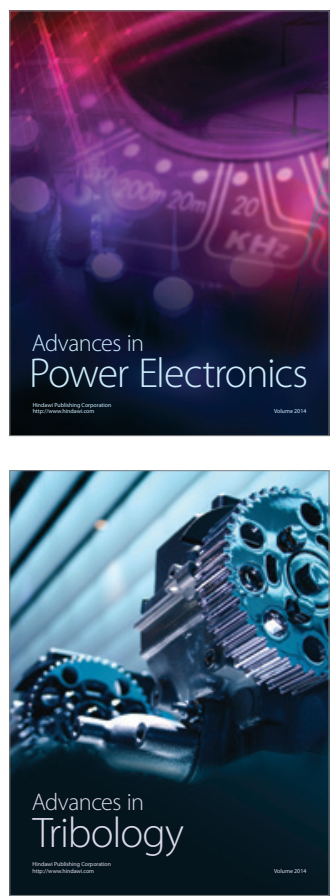

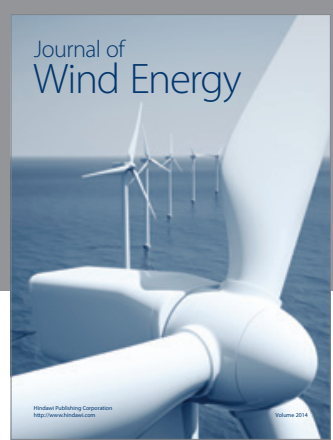

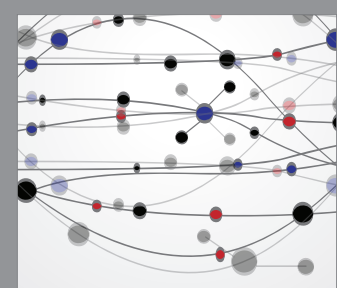

The Scientific World Journal

Submit your manuscripts at http://www.hindawi.com

Journal of

Structures
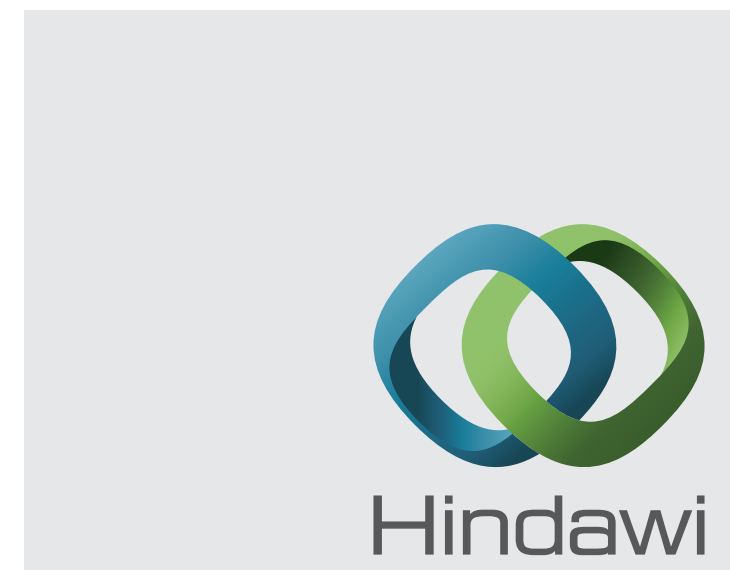

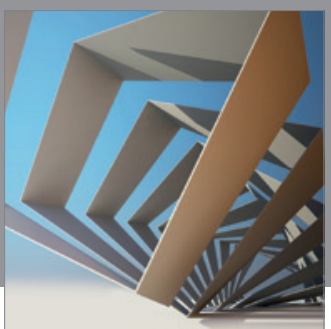

Rotating

Machinery
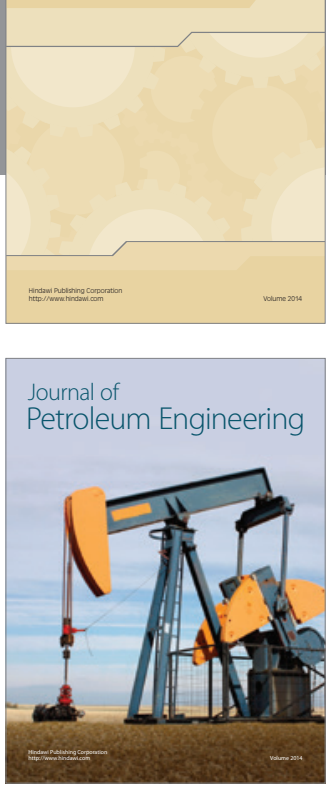

Journal of

Solar Energy
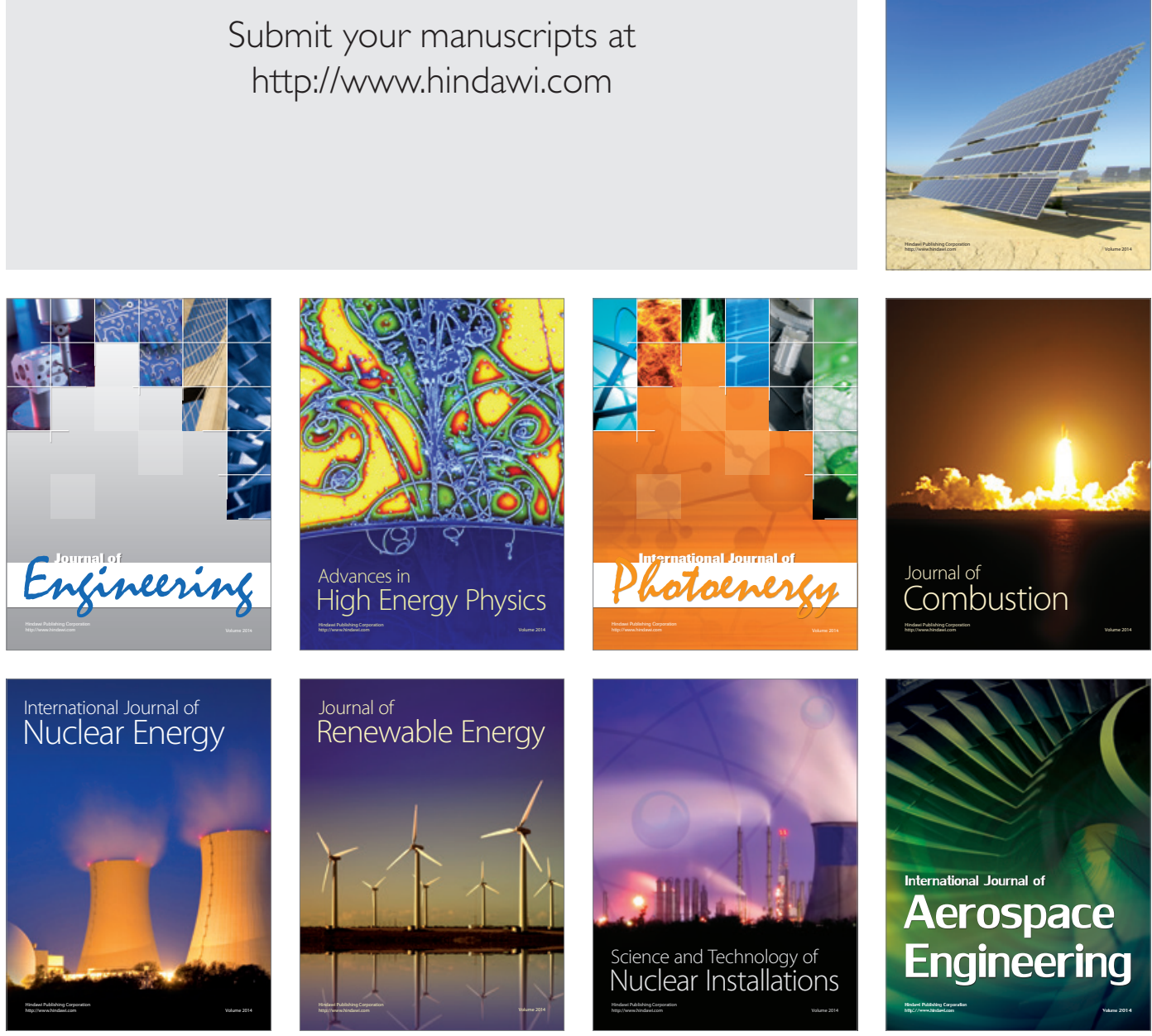